\title{
EXTERNAL SHOCKS AND MONETARY POLICY. DOES IT PAY TO RESPOND TO EXCHANGE RATE DEVIATIONS?
}

\author{
SHOCKS EXTERNOS Y POLITICA MONETARIA. ¿CONVIENE \\ RESPONDER A DESVIACIONES CAMBIARIAS?
}

\section{RODRIGO CAPUTO*}

Central Bank of Chile

\begin{abstract}
There is substantial evidence suggesting that central banks in open economies react to exchange rate fluctuations, in addition to expected inflation and output. In some developing countries this reaction is comparatively larger and it is nonlinear. In an estimated structural macromodel for Chile, this paper assesses the advantages and potential costs of adopting such a reaction function. We conclude that, in the face of most of the external shocks, a policy rule that responds to exchange rate misalignments smooths inflation and output variability, while marginally increasing interest rate fluctuations. On the other hand, for some domestic innovations such a rule performs poorly. When all the shocks are considered at the same time, this rule generates important welfare gains. Finally, when the volatility of external shocks rises, increasing the response to exchange rate misalignments brings welfare improvements. In fact, a more aggressive response to the exchange rate offsets the impact that greater external volatility has on output and inflation, at the cost of inducing higher interest rate fluctuations. In this way, one can interpret the nonlinear reaction to the exchange rate as an optimal response to a more volatile external environment.
\end{abstract}

Keywords: Small Open Economy, Optimal Monetary Policy, Taylor Rules, Exchange Rate.

JEL Classification: E52, E53.

* I am grateful to Peter Tinsley and Petra Geerats for invaluable guidance, and fruitful discussions. I thank participants at the Cambridge University Macro Workshop and Central Bank of Chile Seminar. I also thank two anonymous referees for useful comments on an earlier draft. The views expressed in this paper are solely the responsibility of the author and should not be interpreted as reflecting the views of the Central Bank of Chile or its Board members. Any remaining mistake or misinterpretation is my own.

Email: rcaputo@bcentral.cl Address: Central Bank of Chile, Agustinas 1180, Santiago, Chile. 


\section{Resumen}

Existe importante evidencia que sugiere que los bancos centrales, en economías abiertas, reaccionan a fluctuaciones cambiarias además de reaccionar a la inflación esperada y al producto. En algunos países en desarrollo esta reacción es comparativamente mayor y no lineal. En un modelo macroeconómico estructural para Chile, este documento evalúa las ventajas y potenciales costos de este tipo de funciones de reacción. Concluimos que, frente a la mayoría de los choques externos, una regla de política que responde a desalineamientos cambiarios atenúa la volatilidad de la inflación y el producto, aumentando sólo marginalmente las fluctuaciones de la tasa de interés. Por otro lado, frente a algunos choques domésticos esta regla tiene un mal desempeño. Cuando todos los choques se consideran al mismo tiempo, esta regla genera importante ganancias de bienestar. Por último, cuando la volatilidad de los choques externos se incrementa, responder más agresivamente a desalineamientos cambiarios genera ganancias de bienestar. En particular, una respuesta más agresiva al tipo de cambio contrarresta el impacto que la mayor volatilidad externa tiene sobre el producto y la inflación, a costa de inducir una mayor fluctuación en la tasa de interés. De esta forma, se puede interpretar una reacción no lineal al tipo de cambio como una respuesta óptima a un entorno externo más volátil.

Palabras Clave: Modelos de Economía Abierta, Política Monetaria Optima, Reglas de Taylor, Tipo de Cambio.

Clasificación JEL: E52, E53.

\section{INTRODUCTION}

There is substantial evidence suggesting that central banks in open economies react to exchange rate misalignments, in addition to expected inflation and output. There is, however, some debate as to whether this response improves welfare or not. In general, theoretical and empirical research on this matter have focused on developed economies and, overall, this literature tends to find little role for the exchange rate in monetary policy rules.

On the other hand, in developing economies central banks also react to exchange rate misalignments and, compared to developed countries, this reaction is larger and is nonlinear (see Caputo 2005). In this context, however, there is no formal assessment of the welfare implications of such larger and nonlinear responses. For emerging economies, which face a much more volatile external environment, assessing the advantages and costs of such responses is an important policy question. Hence, the main objective of this paper is to address this issue in a structural model estimated for an emerging economy. 
For developed economies, Clarida, Gali and Gertler (1998) show that the monetary authorities in some European countries and Japan respond to exchange rate misalignments. Schmidt-Hebbel and Tapia (2002) and in Caputo (2005) find that the relative size of this response is larger and is also nonlinear in Chile, a small open and emerging economy. Similarly, Calvo and Reinhart (2002) conclude that many emerging economies use the interest rate as the preferred means of smoothing exchange rate fluctuations. In this case, the "fear of floating" induces many central banks to move interest rates aggressively in response to exchange rate fluctuations.

In this context, there is some controversy as to whether this response is optimal or not. In a theoretical model, Clarida, Gali and Gertler (2001 and 2002) find no role for the exchange rate in the optimal monetary policy rule. In this model, the representative household welfare criterion depends on the variance of domestic inflation and the output. As a result, the feedback rule for the nominal interest rate is qualitatively the same as in closed economies. In particular, there is a lean against the wind response to domestic inflation and, in the absence of cost push shocks, the central bank is able to simultaneously maintain price stability and close the output gap.

More empirically oriented studies also show a small role for the exchange rate. Batini et al. (2003) conclude that an optimal policy rule for the UK should contain a response to the real exchange rate, but only marginal gains are derived from responding to it. In calibrated models for small open economies, Leitemo and Sodestrom (2005) and Caputo (2004) reach similar conclusions: that responding to the exchange rate brings only marginal gains.

The international evidence concerning the role of the exchange rate seems to support the view that there are only marginal benefits from responding to this variable. This is consistent with the evidence presented for some developed countries showing that when the exchange rate enters the policy reaction function its importance, relative to inflation and output, is considerably smaller.

In this context, it is not surprising to observe that in Chile, a small open economy pursuing inflation targeting, the exchange rate forms part of the monetary policy reaction function, as reported in Schmidt-Hebbel and Tapia (2002) and in Caputo (2005). There are, however, two sets of results that do not fit into the international evidence. First, the magnitude of the response to exchange rate deviations is comparatively larger in Chile than in developed economies. In fact, relative to the policy response to expected inflation, the reaction to real exchange rate misalignments is ten times bigger in Chile than in Germany and the UK and eight times bigger than in Japan. ${ }^{1}$ Second, the Chilean central bank reacts more strongly to large deviations in the exchange rate than to small ones.

The evidence described above poses a natural question: what are the advantages, if any, for an emerging economy from adopting a policy rule that responds to real exchange rate misalignments? Or, in other words, is there any specific element in emerging economies that explains a comparatively larger, and nonlinear, response to the exchange rate? The objective of this paper is to address this issue in the context

1 See Caputo (2005) and Clarida, Gali and Gertler (1998). 
of the Chilean economy. In particular, we assess the advantages, and costs, associated with a policy reaction function that contains a response to the exchange rate. This assessment is performed for each individual shock hitting the Chilean economy, as well as for the combination of them.

To address the above issue, we estimate a structural macromodel for Chile. This model, derived implicitly from first principles, ${ }^{2}$ is disaggregated enough to identify different sources of volatility. Once the shocks have been identified, it is possible to assess the performance of alternative monetary policy rules according to standard welfare criteria.

We estimate the model from the period between 1990 and 2000. There are several reasons for doing this and not extending the estimation to 2008: during that period monetary policy was implemented through the use of the short term (90 days) indexed interest rate whereas today it is implemented through a nominal (overnight) interest rate. Also, in that period the exchange rate was not completely free: there was an exchange rate band (that was abandoned in 1999). An finally, after 2000 there were several structural changes in the Chilean economy (see Caputo, Liendo and Medina (2006), Céspedes, Ochoa and Soto (2005) and Caputo and Liendo (2005)).

We conclude that, in the face of most of the external shocks, a policy rule that responds to exchange rate misalignments, as reported in Caputo (2004), has the advantage of smoothing inflation and output fluctuations, while marginally increasing interest rate variability. As a result, responding to exchange rate misalignments is, in this case, welfare improving. On the other hand, for some domestic shocks, such a rule performs poorly. When all shocks are considered at the same time, this rule generates important welfare gains. The reason is that, based on the variance decomposition derived from our structural model, external disturbances are relatively more important than domestic ones.

On the other hand, when the volatility of external shocks rises, increasing the policy response to the exchange rate brings welfare improvements. In fact, a larger response offsets the negative impacts that greater external volatility has on output and inflation. In this way, one can interpret the nonlinear response to the exchange rate, observed in Chile, as an optimal reaction to a more volatile external environment. In this context, it is shown that increasing even further this response does not necessarily generate welfare improvements. In fact, an unusually aggressive response to the exchange rate may exacerbate the volatility of the main macrovariables, increasing the welfare losses.

Finally, given the history of innovations, we derive the optimal policy reaction function. We conclude that the optimal rule entails a positive response to the exchange rate, even though the exchange rate does not enter any of the loss criteria considered in this paper. Furthermore, as is observed in practice, the response to exchange rate misalignments in this optimal rule is quantitatively less important than the response to output and inflation.

2 Examples of compact macromodels, derived from first principles, can be found in Kozicki and Tinsley (2002), Leitemo and Sodestrom (2005), Caputo and Liendo (2005), Lubik and Schorfheide (2007) and Del Negro and Shorfheide (2008). 
This paper is organized as follows. In Section 2, a structural model for a small open economy is specified and estimated for Chile. This is a rational expectations model, implicitly derived from first principles. It contains forward and backwardlooking elements. Section 3 solves the model and analyzes its dynamic properties. In particular, the dynamic responses of this structural model, when faced with a monetary policy innovation, is compared with the dynamics generated in an unrestricted VAR. Section 4 analyzes the dynamics followed by the structural shocks. Section 5 assesses the performance of alternative policy reaction functions in the face of the observed structural shocks. Section 6 studies the role of the exchange rate in monetary policy when external volatility changes. Section 7 analyzes the robustness of the results to normally distributed shocks and finds the optimal policy under a standard welfare criterion. Finally, section 8 concludes the chapter.

\section{A STRUCTURAL MODEL FOR A SMALL OPEN ECONOMY}

As noted by Dennis (2003), most of the micro founded models used in empirical research are calibrated, not estimated. Moreover, these models are tailored to reflect the characteristics of developed countries limiting their applicability to small and emerging economies. In this section we present a micro founded model that is estimated for the Chilean economy. In this way, it is possible to identify the different shocks that this emerging economy faced and the welfare implications of alternative policy rules.

Following Svensson (2000), Gali and Monacelli (2005), and Leitemo and Sodestrom (2005) we lay down a model for a small open economy that is derived from first principles. In particular, the aggregate demand and supply equations are derived from the optimizing behavior of consumers and firms. We also specify the term structure of interest rates, relating the long-term interest rate to short-term one, and the uncovered interest rate parity condition (UIP) expressed in real terms. As it is common in the literature ${ }^{3}$ some of the exogenous processes are allowed to follow an autoregressive process of order one. Finally, the model is closed with a monetary policy reaction function relevant for Chile and estimated in Caputo (2005). As noted by Kozicki and Tinsley (2002), in principle all parameters in the minimalist trenddeviation model are based on specifications of the utility functions and resource constraints of households, firms, and bond traders in the economy. The model is represented by the following equations:

$$
\begin{gathered}
y_{t}=a_{1} E_{t}\left(y_{t+1}\right)+a_{2} y_{t-1}+a_{3} \rho_{t, n}+a_{4} q_{t}+a_{5} y_{t}^{*}+\varepsilon_{y, t} \\
\pi_{t}=b_{1} E_{t} \pi_{t+1}+b_{2} \pi_{t-1}+b_{3} y_{t}+b_{4} q_{t}+b_{5} \Delta q_{t}+\varepsilon_{\pi, t}
\end{gathered}
$$

3 See Svensson (2000) and Leitemo and Soderstrom (2005). 


$$
\begin{gathered}
\rho_{t, n}=c_{1} E_{t}\left(\rho_{t+1, n}\right)+c_{2} \rho_{t}+\varepsilon_{\rho_{n}, t} \\
q_{t}=E_{t}\left(q_{t+1}\right)+d_{1}\left(\rho_{t}^{*}-\rho_{t}\right)+d_{2} \text { Risk }_{t}+\xi_{q, t}
\end{gathered}
$$

where the variables are expressed as deviations from the steady state levels. Equation (1) is an aggregate demand equation in which the output gap, $y_{t}$, responds to the $n-$ period long-term real interest rate, $\rho_{t, n}$, but also to open economy variables such as the real exchange rate, $q_{t}$, and the foreign level of output, $y_{t}^{*}$. On the other hand, the existence of habits in the consumer's utility function implies that past and expected output enters this specification. In particular, Caputo (2005) shows that, from the Euler equation for consumption, it is possible to derive expressions in which $a_{1}$ and $a_{2}$ are an increasing function of the degree of habits. In the limiting case in which habits are not present, $a_{1}=a_{2}=0$. Following Leitemo and Soderstrom (2005), we impose the restriction $a_{1}=1-a_{2}$. Finally, the aggregate demand disturbance $\varepsilon_{y, t}$ is often interpreted as a preference shock and, in the case of Chile, it is assumed to be white noise.

An increase in $\rho_{t, n}$ induces economic agents to substitute current consumption for saving. Hence, $a_{3}$ is expected to be negative. On the other hand, $q_{t}$ has a direct impact on the aggregate demand. A depreciation, for instance, makes domestically produced goods relatively cheaper. As a consequence, economic agents, in the home economy and abroad, substitute foreign goods by domestically produced ones. Hence, a depreciation has an expansionary impact on domestic output, and consequently $a_{4}$ is expected to be positive. As shown by Gali and Monacelli (2005), Caputo (2005), and Parrado and Velasco (2002), $a_{4}$ depends on few structural coefficients: the degree of openness in the small economy and the elasticity of substitution between foreign and domestically produced goods. Finally, $y_{t}^{*}$ has an expansionary impact on the aggregate demand and therefore $a_{5}$ is expected to be positive.

Equation (2) represents the hybrid New Keynesian Phillips Curve (NKPC) that describes the behavior of Consumer Price Inflation (CPI), $\pi_{t}$, in an open economy. This specification is hybrid because it reflects the behavior of two types of firms. The first type, forward-looking firms, set prices optimally, given the constraints on the timing of adjustments and using all the available information in order to forecast future marginal costs. The second type, backward-looking firms, use a simple rule of thumb that is based on the past history of aggregate price behavior. In this context, Gali and Gertler (1999) show that lagged and expected inflation will enter the NKPC and, when the discount factor is one $b_{1}=1-b_{2} \cdot{ }^{4}$

On the other hand, domestic output, $y_{t}$, has a positive impact on marginal costs and, consequently, on the general level of prices. As a consequence, it is expected that $b_{3}>0$. Finally, as noted by Caputo (2004) in an open economy the level and the first difference of the real exchange rate, $q_{t}$, impact CPI inflation. In fact, an increase in $q_{t}$ increases the price of some intermediates inputs and shifts foreign and domestic

4 Similar specifications are found in Svensson (2000) and Christiano, Eichenbaum and Evans (2005). 
demand towards domestically produced goods. As a consequence domestic and CPI inflation increase. Therefore, it is expected that $b_{4}>0$. On the other hand, a change in CPI inflation, $\Delta q_{t}$, affects the imported component of $\pi_{t}$. Hence, it is expected that $b_{5}>0$.

Equation (3) relates the long-term real interest rate, $\rho_{t, n}$, to the short-term real interest rate, $\rho_{t}$. In particular, this specification is derived, as in Fuhrer and Moore (1995), from the intertemporal arbitrage condition that equalizes the expected real holding-period yields on a long-term bond and the real return on a short-term central bank instrument. As shown in Fuhrer and Moore (1995) $c_{1}$ and $c_{2}$ are positive and it is expected that $c_{1}+c_{2}=1$.

In this model the real exchange rate, $q_{t}$, evolves according to equation (4) which is the uncovered interest rate parity condition (UIP) expressed in real terms. The variable $\left(\rho_{t}^{*}-\rho_{t}\right)$ represents the real interest rate differential, where $\rho_{t}^{*}$ is the real ex-post foreign interest rate. On the other hand, $\rho_{t}$ is the domestic real ex-post interest rate, which in the case of Chile is the monetary policy instrument. The Risk ${ }_{t}$ variable is a country risk proxy for Chile, constructed as in Gallego, Hernandez and SchmidtHebbel (2002). The residual of this equation, $\xi_{q, t}$, represents the risk elements not captured by the rest of the variables. If the UIP holds, $d_{1}=1$ and $d_{2}>0$.

Now, following Svensson (2000), Batini, Harrison and Millard (2003) and Leitemo and Sodestrom (2005), we model Risk $k_{t}$ as an autoregressive processes of order one. In addition, we allow the real exchange rate disturbances, $\xi_{q, t}$, to be autocorrelated. ${ }^{5}$ Hence Risk ${ }_{t}$ and $\xi_{q, t}$ can be expressed as:

$$
\begin{gathered}
\xi_{q, t}=\varphi_{0}^{1}+\varphi_{q} \xi_{q, t-1}+\varepsilon_{q, t} \\
\operatorname{Risk}_{t}=\varphi_{0}^{0}+\varphi_{r i} \operatorname{Risk}_{t}+\varepsilon_{\text {Risk }, t}
\end{gathered}
$$

The foreign variables, $y_{t}^{*}$ and $\rho_{t}^{*}$ are assumed to follow processes that are independent from the small open economy. Furthermore, and following Svensson (2000), we model them as autoregressive processes of order one. Estimating those processes on monthly basis gives the following results:

$$
\begin{gathered}
y_{t}^{*}=0.910 y_{t-1}^{*}+\varepsilon_{y *, t} \\
\rho_{t}^{*}=0.934 \rho_{t}^{*}+\varepsilon_{\rho^{*}, t}
\end{gathered}
$$

Finally, we closed the model with a policy reaction function relevant for Chile. This has been estimated in Caputo (2005) as an inflation forecast based (IFB) rule that allows for a response to exchange rate deviations. This IFB rule can be described, on a monthly basis, as

5 The other structural disturbances do not present a persistent behavior. 


$$
\rho_{t}=0.878 \rho_{t}+(1-0.878)\left(0.786 E_{t}\left(\pi_{t+15}\right)+1.122 y_{t-1}+0.633 q_{t}\right)+\varepsilon_{r, t}
$$

where $\rho_{t}$ is the ex-post real interest rate which is the monetary policy instrument used by the Chilean central bank. This instrument reacts to expected inflation fifteen months ahead, $E_{t}\left(\pi_{t+15}\right)$, to the lagged output gap, $y_{t-1}$ and to the real exchange rate, $q_{t} \cdot{ }^{6}$ The monetary policy shock is captured by $\varepsilon_{r, t}$.

\subsection{Estimation}

In general, open economy models, as the one described previously, are estimated on a quarterly basis and, in the case of Chile, the equations are estimated individually. One of the innovations of this paper is that such a model is estimated as a system on a monthly basis. Estimating equations individually may generate inconsistent estimates. On the other hand, even if single equation estimates are consistent (OLS instrumental variables, for instance), they are not efficient when compared to estimators that make use of all the cross-equation correlation of the disturbances.

We estimate the model from the period between 1990 and 2000. There are three reasons for doing this and not extending the estimation to 2008. First, during that period monetary policy was implemented through the use of the short term (90 days or overnight) indexed interest rate whereas today it is implemented through a nominal (overnight) interest rate. Second, in that period the exchange rate was not completely free: there was an exchange rate band (that was abandoned in 1999). As a result, the importance of the real exchange rate in the policy reaction function has changed after 2000 (see Caputo, Liendo and Medina (2006)). Third, after 2000 there were several structural changes in the Chilean economy. In particular, prices and wages became more sticky and less persistent, whereas the policy response to the exchange rate declined (see Caputo, Liendo and Medina (2006), Céspedes, Ochoa and Soto (2005) and Caputo and Liendo (2005)).

To estimate the system of equations (1) to (6) we use two alternative procedures, Full Information Maximum Likelihood (FIML) and the Generalized Method of Moments (GMM). In general, the results support both the hybrid NKPC and an aggregate demand equation containing forward and backward-looking components. The results are, however, more precise with the GMM method. The reason for this is that, in some equations, residuals are not normally distributed and, in this case, GMM generates efficiency gains when compared to FIML.

On the other hand, inflation and output may react with some lags to innovations in the rest of the variables. This is more likely to happen in the case of models expressed on a monthly frequency. Therefore, when estimating the system we allow for lagged responses to all the variables. In practice, this means that we include several lags of the right-hand side variables in each equation and then drop, sequentially, the lags with no significant coefficients. The final results are presented, for the FIML and GMM methods, in Table 1.

6 The targeting horizon for inflation, fifteen months, is consistent with the way in which the Chilean central bank targets inflation. On the other hand, the response to the lagged output gap reflects the lag in the availability of information (see Caputo (2005)). 


\section{TABLE 1}

STRUCTURAL COEFFICIENTS ESTIMATES 1990-2000

(Standard errors in parenthesis)

\begin{tabular}{|c|c|c|c|}
\hline Coefficients & Variable & $\begin{array}{c}\mathrm{GMM}^{a} \\
\text { Estimate }\end{array}$ & $\begin{array}{c}\text { FIML }^{b} \\
\text { Estimate }\end{array}$ \\
\hline$a_{1}$ & $E_{t}\left(y_{t+1}\right)$ & $\begin{array}{c}0.453^{c} \\
\text { (n.a.) }\end{array}$ & $\begin{array}{c}0.454^{c} \\
\text { (n.a.) }\end{array}$ \\
\hline$a_{2}$ & $y_{t-1}$ & $\begin{array}{c}0.547^{* *} \\
(0.00)\end{array}$ & $\begin{array}{c}0.546^{* * *} \\
(0.00)\end{array}$ \\
\hline$a_{3}$ & $\rho_{n, t-3}$ & $\begin{array}{c}-0.007^{* *} \\
(0.00)\end{array}$ & $\begin{array}{c}-0.002 \\
(0.01)\end{array}$ \\
\hline$a_{4}$ & & $\begin{array}{c}0.016^{* *} \\
(0.00)\end{array}$ & $\begin{array}{c}0.016^{*} \\
(0.01)\end{array}$ \\
\hline$a_{5}$ & $\left(\Delta y_{t-8}^{*}\right)^{d}$ & $\begin{array}{c}0.026^{* *} \\
(0.00)\end{array}$ & $\begin{array}{c}0.025^{*} \\
(0.01)\end{array}$ \\
\hline$b_{1}$ & $E_{t} \pi_{t+1}$ & $\begin{array}{c}0.562^{c} \\
\text { (n.a.) }\end{array}$ & $\begin{array}{c}0.527^{c} \\
\text { (n.a.) }\end{array}$ \\
\hline$b_{2}$ & $\pi_{t-1}$ & $\begin{array}{c}0.438^{* *} \\
(0.02)\end{array}$ & $\begin{array}{c}0.483^{* *} \\
(0.04)\end{array}$ \\
\hline$b_{3}$ & $y_{t-3}$ & $\begin{array}{c}0.067^{* *} \\
(0.01)\end{array}$ & $\begin{array}{l}0.046 \\
(0.10)\end{array}$ \\
\hline$b_{4}$ & $q_{t-8}$ & $\begin{array}{c}0.035^{* *} \\
(0.02)\end{array}$ & $\begin{array}{c}0.035^{* *} \\
(0.02)\end{array}$ \\
\hline$b_{5}$ & $\Delta q_{t-5}$ & $\begin{array}{c}0.203^{* *} \\
(0.07)\end{array}$ & $\begin{array}{l}0.108 \\
(0.13)\end{array}$ \\
\hline$c_{1}$ & $E_{t}\left(\rho_{t+1, n}\right)$ & $\begin{array}{c}0.941^{* *} \\
(0.00)\end{array}$ & $\begin{array}{c}0.931^{* *} \\
(0.03)\end{array}$ \\
\hline$c_{2}$ & $\rho_{t}$ & $\begin{array}{c}0.060^{* *} \\
(0.00)\end{array}$ & $\begin{array}{c}0.070^{* * *} \\
(0.03)\end{array}$ \\
\hline$d_{1}$ & $\left(\rho_{t}^{*}-\rho_{t}\right)$ & $\begin{array}{c}1.082^{* *} \\
(0.00)\end{array}$ & $\begin{array}{c}0.935^{* *} \\
(0.20)\end{array}$ \\
\hline$d_{2}$ & Risk $_{t}$ & $\begin{array}{c}2.354^{* *} \\
(0.00)\end{array}$ & $\begin{array}{c}2.024^{* * *} \\
(0.36)\end{array}$ \\
\hline$\varphi_{\text {Risk }}$ & Risk $_{t-1}$ & $\begin{array}{c}0.881^{* *} \\
(0.00)\end{array}$ & $\begin{array}{c}0.858^{* *} \\
(0.05)\end{array}$ \\
\hline$\varphi_{q}$ & $\xi_{q, t-1}$ & $\begin{array}{c}0.727^{* *} \\
(0.00)\end{array}$ & $\begin{array}{c}0.776^{* *} \\
(0.06)\end{array}$ \\
\hline
\end{tabular}

a GMM Instrumental Variables. The set of instruments contains the following variables:

$y_{t-1}, \ldots y_{t-6}, \pi_{t-1}, \ldots, \pi_{t-5}, q_{t-1}, q_{t-3}, \ldots, q_{t-7}, \rho_{n, t-3}, \ldots, \rho_{n, t-5}, \rho_{t}, \Delta y_{t-8}^{*}, \rho_{t-1}^{*}$, Risk $_{t}, \ldots$, Risk $_{t-3}$.

$b$ Uses Berndt-Hall-Hall-Hausman (BHHH) optimization algorithm. If Marquard algorithm is used, results do not change. Residuals failed the normality and heteroscedasticity tests in the following equations: NKPC, the term structure equation and the real UIP.

$c \quad$ Restricted.

$d \quad$ The $y_{t}^{*}$ series is $\mathrm{I}(1)$, hence, we use $\Delta y_{t}^{*}$.

$* *$ Significant at $99 \%$ and, * significant at $95 \%$. Standard errors in parenthesis. 
The estimation period is September 1990, which is the formal date in which inflation targeting was adopted, to December 2000. As in Caputo (2005), the variables are expressed as cyclical deviations from trend. In computing each variable, we follow Harvey and Jaeger (1993) and fit a structural time series model for each series (being the exemption the interest rates, and risk). This procedure, and the advantages involved in it, is described in Harvey and Jaeger (1993) and Caputo (2005). A detailed description of each series is presented in the Appendix.

Finally, $y_{t}, \pi_{t}, q_{t}$ and $y_{t}^{*}$ are expressed on a monthly basis, whereas $\rho_{t}, \rho_{n, t}$, $\varphi_{t}$ and $\rho_{t}^{*}$ are all expressed on an annual basis. In this context, in order to interpret properly the output response to the long-term interest rate, $a_{3}$, and the $d_{1}$ and $d_{2}$ coefficients in the UIP equation, we introduce, in equation (1) and (4), the variables $\rho_{t}, \rho_{n, t}, \varphi_{t}$ and $\rho_{t}^{*}$ on a monthly basis. ${ }^{7}$

\subsection{Discussion of Results}

As it was previously mentioned, the GMM procedure gives more precise estimates. Hence, in what follows, we will discuss those results rather than those obtained by FIML.

The results presented in Table 1 support an aggregate demand equation in which the forward and backward-looking components are present. In particular, the output level presents an important degree of persistence, $a_{2}=0.548$. On the other hand, the long-term real interest rate has a negative impact on output after five months. This timing is consistent with the result obtained by García, Herrera and Valdés (2002) for an aggregate demand estimated on a quarterly basis for Chile. Exchange rate and foreign output do have a positive impact on domestic output with a delay of four and eight months respectively, this timing is, again, roughly consistent with the one found in García, Herrera and Valdés (2002).

The hybrid NKPC is supported by the data. In particular, there is an important degree of inflation persistence, $b_{2}=0.451$. When compared to the evidence for the USA and Europe, presented in Gali and Gertler (1999) and Clarida, Gali and Gertler (2001) respectively, it turns out that in Chile the inflation persistence is twice as much. One possible explanation is the high degree of indexation in the Chilean economy, in particular, in the early nineties. On the other hand, domestic output and the level of real exchange rate do impact inflation with a delay of one and two quarters respectively. The rate of depreciation, $\Delta q_{t}$, do have a positive effect on inflation after five months. The coefficient associated to the depreciation, $b_{4}$ is 0.152 .

The coefficients in the term structure equation are positive as expected. Furthermore, $c_{1}+c_{2}=1$, which is in line with Fuhrer and Moore (1995).

Estimating the UIP condition, expressed in real terms, gives coefficients with the expected sign. In particular, $d_{1}>0$ and $d_{2}>0$. However, the fact that $d_{1}$ is well below one indicates a partial failure of the UIP. This partial failure is also reported in Fujii and Chin (2000) for developed countries and in Garcia, Herrera and Valdés (2002) for

7 For instance, the policy interest rate on a monthly basis, $\rho_{t}^{m}$, is expressed as $\rho_{t}^{m}=\left\{\left(1+\rho_{t}\right)^{(1 / 12)}-1\right\}$. 
Chile. One potential reason for this partial failure is that capital controls, in place in Chile in the nineties, may have attenuated the impact of interest rate differentials on the exchange rate. As it will be shown in the next section, although our results deviate somehow from the UIP condition, the exchange rate dynamics does follow the path that we expect from theory. Hence, we use the results obtained here and do not impose, as in Garcia, Herrera and Valdés (2002), any restriction into the UIP equation.

The risk premium variable, $R i s k_{t}$, and the exchange rate residual, $\xi_{q, t}$, do present an important degree of persistence. This feature is also present in the UK economy, as reported by Batini, Harrison and Millard (2003).

Finally, we perform a Chow test of structural breaks to see whether the equations in the estimated system are stable or not. This test is performed for two potential break point dates, 1994.12 and $1996.12 .^{8}$ For both dates, there is no evidence of structural breaks in the aggregate demand equation, the NKPC, the UIP condition and the term structure equation.

\section{MODEL SOLUTION AND DYNAMICS}

In order to analyze the dynamic properties of the structural model, we first solve it and then analyze the impulse response functions (IRFs) to different structural shocks. In particular, we compare the IRF to a monetary policy innovation in both the structural model and an unrestricted VAR. In this case, this innovation has a structural interpretation in both cases and, therefore, the IRFs are comparable. This type of comparison are performed, for the USA, in Christiano, Eichenbaum and Evans (1999) and (2005).

\subsection{Model Solution}

The model is a linear perfect foresight one. It can be characterized by a vector of nine variables, $x_{t}^{\prime}=\left(y_{t}, \pi_{t}, \rho_{n, t}, q_{t}, \rho_{t}\right.$, Risk $\left._{t}, \xi_{q, t}, y_{t}^{*}, \rho_{t}^{*}\right)$ and a vector of eight structural innovations, $\varepsilon_{t}^{\prime}=\left(\varepsilon_{y, t}, \varepsilon_{\pi, t}, \varepsilon_{\rho_{n}, t}, 0, \varepsilon_{\rho, t}, \varepsilon_{R i s k, t}, \varepsilon_{q, t}, \varepsilon_{y^{*}, t}, \varepsilon_{\rho^{*}, t}\right)$. The state representation of the whole system can be cast in the format

$$
\sum_{i=1}^{\vartheta} H_{i} E_{t} x_{t+i}+\sum_{i=-k}^{0} H_{i} x_{t+i}=\varepsilon_{t}
$$

8 Between those dates there is a change in the volatility of supply and country risk shocks. This issue is discussed further in Section 6. 
where $H_{i}$ are square matrices containing the estimated structural coefficients. The parameters $\vartheta$ and $k$ represent, respectively, the maximum number of leads and lags in the system. In this model the policy reaction function, equation (9), contains the maximum number of leads, $\vartheta=15$, and the aggregate demand function, equation (1), contains the maximum number of lags $\mathrm{k}=9$.

Now, the model can be solved, as in Fuhrer and Moore (1995b), using the generalized saddlepath procedure of Anderson and Moore (1985), also know as the AIM algorithm. In doing so, it is assumed that $E_{t}\left(\varepsilon_{t+i}\right)=0$ for $i>0$.

Now, for a given set of initial conditions, if the system has a unique solution that grow no faster than a given upper bound, this procedure generates a representation of the model that is called the observable structure;

$$
S_{0} x_{t}=\sum_{i=1}^{9} S_{-i} x_{t-i}+\varepsilon_{t}
$$

Equation (11) is a structural representation of the model because it is driven by the structural disturbance vector, $\varepsilon_{t}$. The coefficient matrix $S_{0}$ contains the contemporaneous relationships among the elements of $x_{t}$. This is an observable representation of the model because it does not contain unobservable expectations.

Now it is possible to generate the reduce form of the structural model. In fact, premultiplying equation (11) by $S_{0}^{-1}$ gives the autoregression;

$$
x_{t}=\sum_{i=1}^{9} S_{0}^{-1} S_{-i} x_{t-i}+S_{0}^{-1} \varepsilon_{t}
$$

In order to generate impulse-responses functions of the estimated model, we use the VAR representation in (12), and the fact that $S_{0}^{-1}$ and $B_{-i}=S_{0}^{-1} S_{-i}$ for $i=1$ to 9 are known, to compute the response of a variable $i$ to structural disturbance $j ; \frac{\partial x_{i, t}}{\partial \varepsilon_{j t}}$.

\subsection{Model Dynamics}

The model is solved using the AIM algorithm and, despite the fact that the model contains fifteen leads and nine lags, there is a unique solution. Hence it is possible to obtain both the observable structure of the model, equation (11), and the VAR representation of it, equation (12). It is also possible to derive the IRF to every single structural shock in the $\varepsilon_{t}$ vector.

\subsubsection{Impulse Response to a Monetary Policy Innovation}

We compare the dynamics generated by the structural model and that obtained from a VAR. In particular, we estimate an unrestricted VAR for the $x_{t}$ vector and 
compute the IRF to a monetary policy innovation. ${ }^{9}$ Then, we compute the IRF to a monetary policy shock in the structural model and compare both IRFs. As noted by Valdes (1997) and Keating (1992), in an unrestricted VAR the only innovation with structural interpretation is the monetary policy one. Hence, both innovations have a structural interpretation and their IRFs can be compared. Figure 1 shows the IRFs in each case.

\section{FIGURE 1}

RESPONSES TO A $1 \%$ MONETARY POLICY SHOCK

(Dotted line VAR, solid line Structural Model, percentage change)


After an increase in the interest rate, the monetary policy instrument, output contracts. The maximum impact of this policy innovation is reached after ten months, in the case of the structural model (solid line), and after nine months in the case of the

9 The unrestricted VAR contains two lags, choosen with the Akaike criterion and, it uses the lower triangular Cholesky decomposition to identify the shocks. 
unrestricted VAR (dotted line). The output contraction is more severe in the structural model and its recovery is also slower.

In the structural model, the real exchange rate appreciates on impact after an increase in the real interest rate. Then, the exchange rate depreciates and returns to its equilibrium level after forty months. In the case of the VAR, the exchange depreciates. This depreciation, denominated "exchange rate puzzle", is also reported for Chile in Parrado (2001) and, it is absent from the structural model. ${ }^{10}$

In the face of a monetary policy innovation, inflation contracts since the beginning in the structural model, reaching its lower level after eight months. Then, it returns to its equilibrium after thirty months. In the case of the VAR, inflation increases, initially, and then it goes down. This initial increase, denominated "inflation puzzle", is also found (for the price level) in Parrado (2001). Again this puzzle is absent from the structural model. The path followed by both IRFs is quite similar, however, inflation contracts more, and for more time, in the structural model. The reason for this is that, as we previously discussed, in the structural model output and exchange rate contract by more, contributing to an even lower rate of inflation.

On the other hand, in the structural model and in the VAR, the interest rate returns to its initial level after twenty months of the initial shock. In both cases the interest rate follows almost the same path.

Overall, the structural model tends to replicate quite well the dynamics found in an unrestricted VAR for output, inflation and interest rate. Furthermore, the exchange rate and inflation puzzles are absent in this model. Hence, there is no need to impose restrictions, like those in Parrado (2001), to eliminate those puzzles.

Now, we analyze the dynamic properties of the model when faced to the other domestic and foreign innovations. In this case, the IRFs obtained are not directly comparable to those derived from the unrestricted VAR. The reason is that a VAR, that uses a lower triangular Cholesky decomposition to identify innovations, does not generate, necessarily, IRFs with structural interpretation. In fact, the IRFs derived from a VAR are likely to reflect a combination of structural innovations and, as a consequence, standard VAR analysis will be difficult to interpret in a structural way (see Keating 1992). Therefore, we limit our analysis to the IRFs obtained from the structural model.

\subsubsection{Impulse Responses to Domestic Shocks}

An aggregate demand innovation, $\varepsilon_{y, t}$, generates an output increase during the first twenty months after the innovation (see Figure 2). As a consequence, marginal costs increase and therefore inflation raises. This increase in inflation reaches its maximum level seven month after the shock. The central bank responds to the rise in inflation an output by increasing the policy interest rate. This reaction has its peak nearly ten month after the initial shock and then, the interest rate converges to its initial level.

10 To overcome this puzzle, Parrado (2001) estimated a structural VAR that imposses long-term restrictions. 
As a result of a higher interest rate the real exchange rate appreciates considerably during the first ten months and then, it slowly returns to its equilibrium level.

\section{FIGURE 2}

STRUCTURAL MODEL: RESPONSES TO A ONE SD AGGREGATE DEMAND SHOCK (Percentage change)
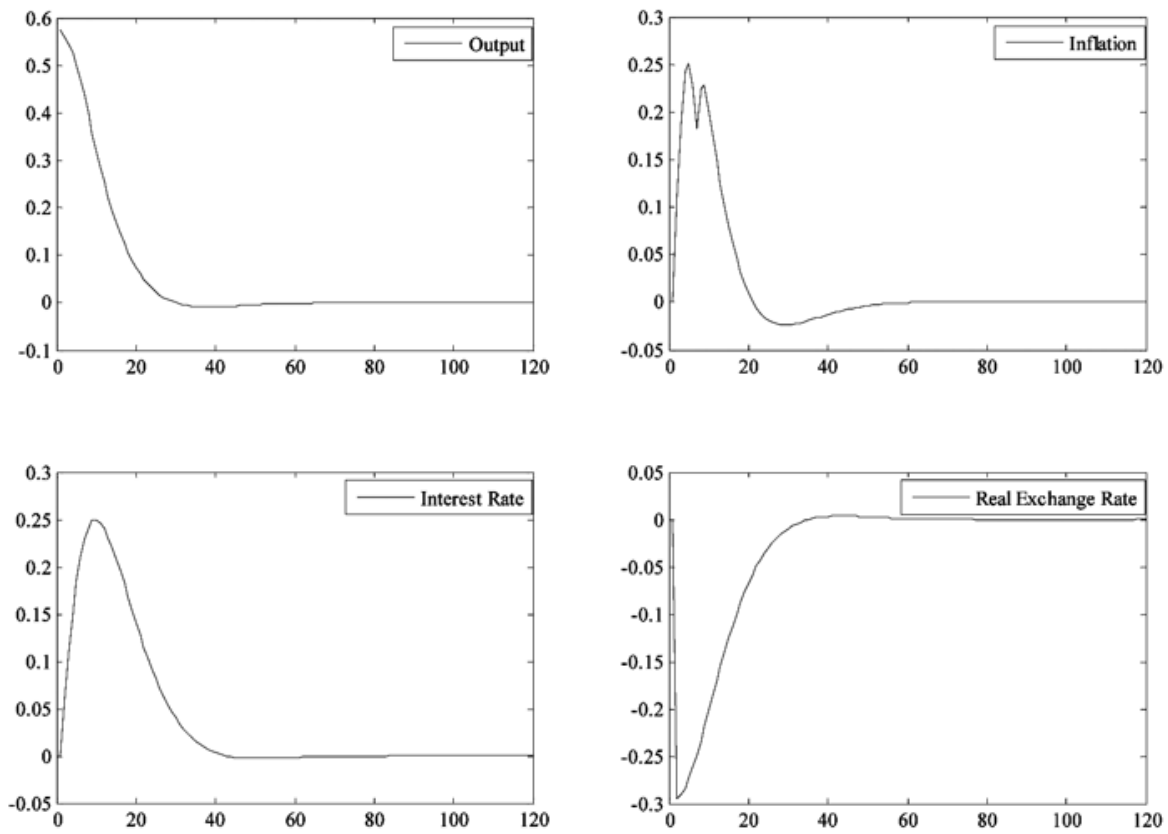

When the economy is subject to an aggregate supply shock, $\varepsilon_{\pi, t}$, inflation increases in the first ten months (Figure 3). The central bank reacts by increasing the interest rate and, as a consequence, output and the real exchange contract. Inflation returns to its initial level after twenty months. In this case, it is possible to stabilize the economy with a non very aggressive increase in interest rate. The reason for this is that inflation is determined, in an important way, by expected inflation and, in this model, agents expect inflation to be lower in the future. ${ }^{11}$ This fact generates, by itself, a reduction in inflation without increasing interest rates further. In other words, the sacrifice ratio goes down with the degree of forward-looking behavior in inflation.

11 In this model, the structure of the economy and the policy reaction function are known to agents. 
In fact, in the limiting case in which inflation is completely forward-looking and there is no inflation persistence, $b_{2}=0$, stabilizing the economy after a supply shock comes at no cost in terms of output and interest rate. Of course, this is an extreme case, and the evidence, in Chile and abroad, indicates that inflation shocks do generate contractions in output.

\section{FIGURE 3}

STRUCTURAL MODEL: RESPONSES TO A ONE SD AGGREGATE SUPPLY SHOCK

(Percentage change)
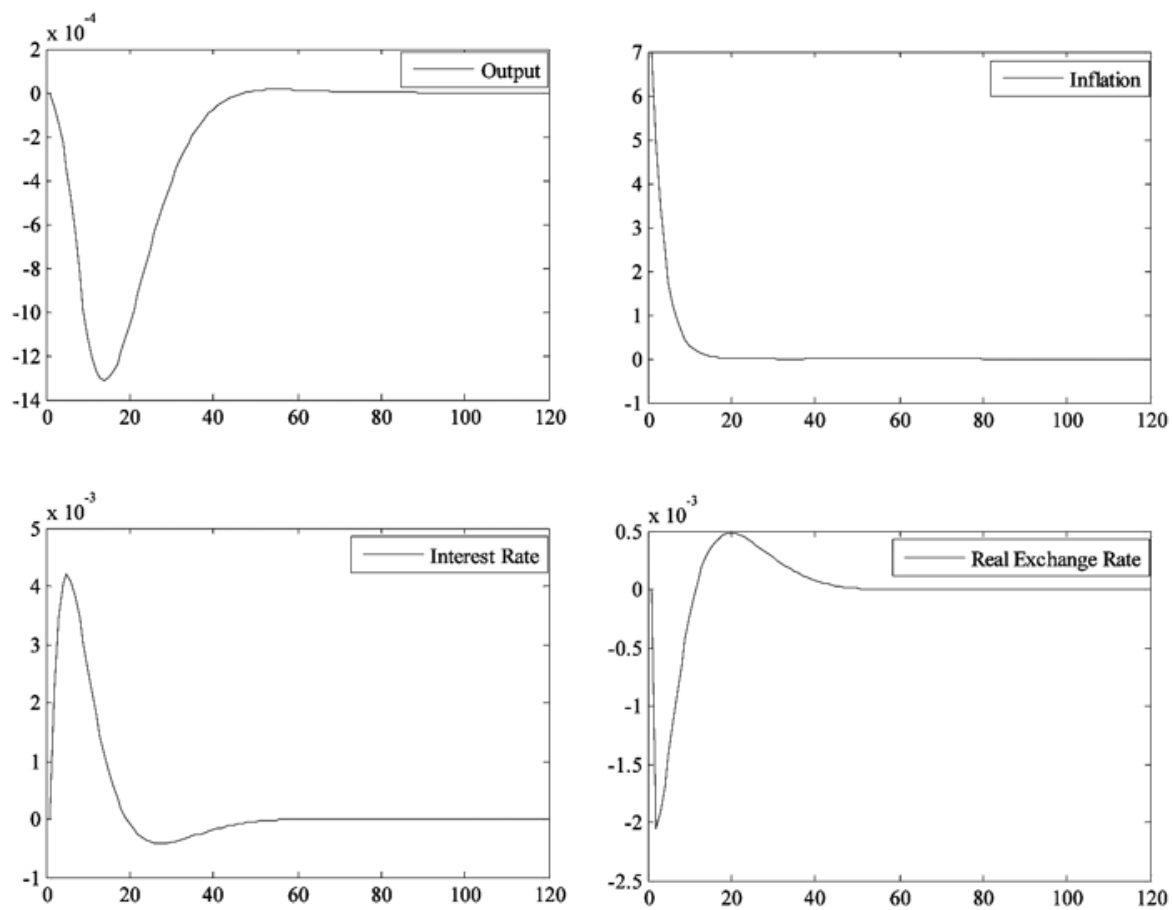

A positive innovation in the term premium, $\varepsilon_{\rho_{n}, t}$, generates an increase in the long-term real interest rate and, as a result, a contraction in output for almost twenty months (Figure 4). This contraction in output, in turn, generates a decrease in marginal cost and a reduction in inflation for nearly thirty months. Now, because the central bank is targeting inflation with a concern for output as well, the monetary policy response to this reduction in output and inflation is to reduce the interest rate. This reduction generates a real depreciation in the first thirty five months after the initial shock. 


\section{FIGURE 4}

STRUCTURAL MODEL: RESPONSES TO A ONE SD TERM PREMIUM SHOCK

(Percentage change)
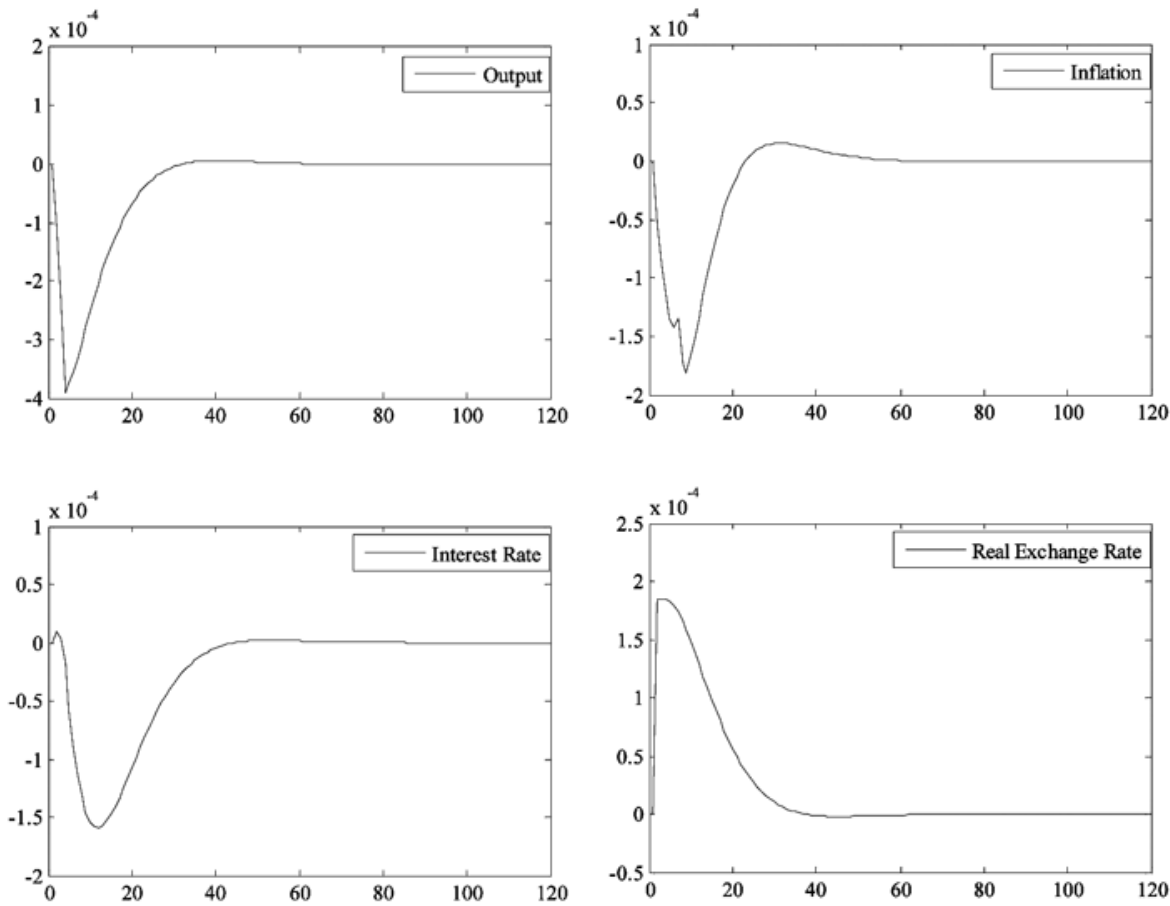

\subsubsection{Impulse Responses to Foreign Shocks}

A country risk shock, $\varepsilon_{\text {Risk,t }}$, generates a real depreciation in the first ten months (Figure 5). As a consequence, output increases -a depreciation has an expansionary impact on output. This output expansion, together with the real depreciation, contribute to an increase in inflation. The central bank reaction is to rise the interest rate during the first thirty months after the innovation. This pattern of responses has been also found in Parrado (2001), who using a structural VAR, concludes that a risk premium shock increases output and inflation and generates an increase in interest rates.

On the other hand, a real exchange rate shock, $\varepsilon_{q, t}$, not related to country risk or interest rate differential, generates a real depreciation that persists for seven months (Figure 6). This depreciation expands output in the first twenty months. Inflation increases as a consequence of higher marginal costs, derived from a higher level of output and a depreciated real exchange rate. The initial depreciation increases, also, the price of imported goods which expands inflation further. 


\section{FIGURE 5}

STRUCTURAL MODEL: RESPONSES TO A ONE SD COUNTRY RISK SHOCK

(Percentage change)
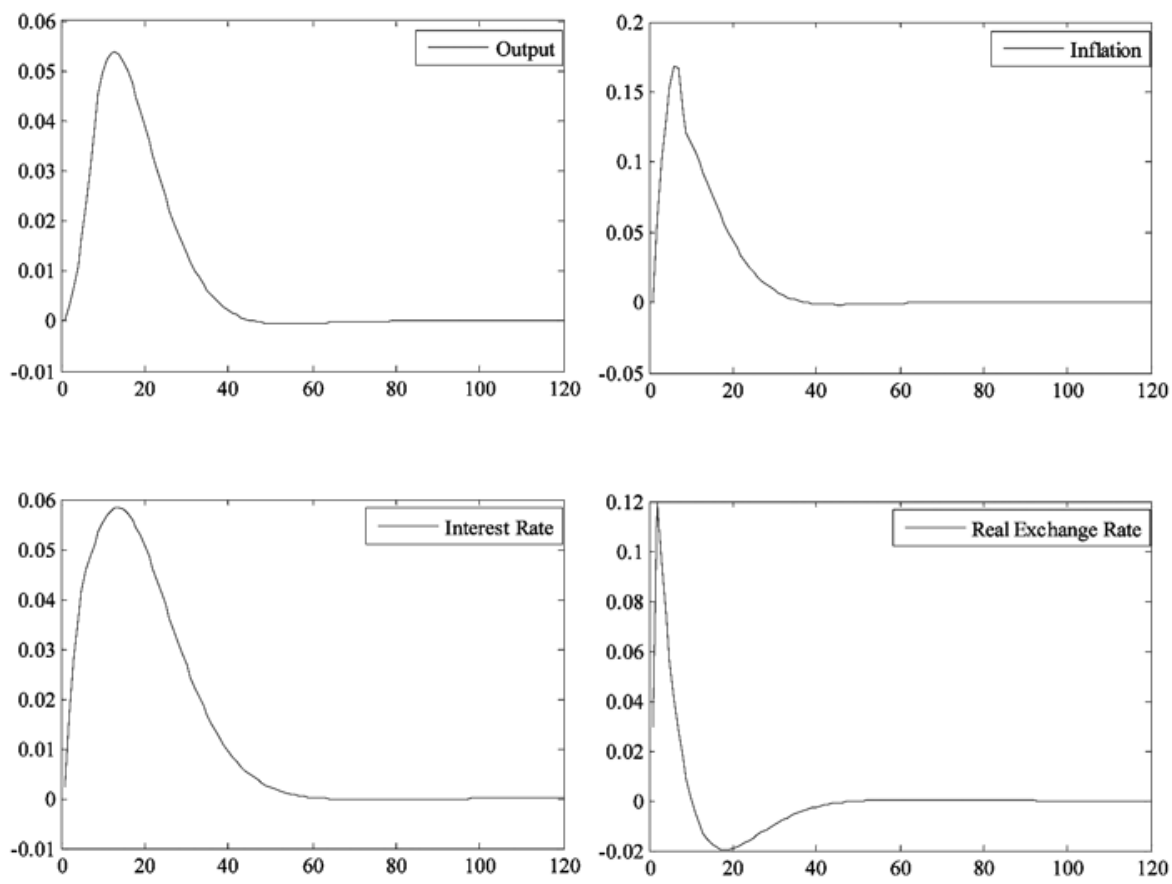

When output in the rest of the world experiences a transitory innovation, $\varepsilon_{y^{*}, t}$, domestic output expands during the first twenty months (Figure 7). Inflation increases, and as a consequence of this, the central bank adopts a contractive monetary policy. This increase in interest rate generates a reduction in the interest rate differential and, consequently, a real appreciation that lasts for twenty months.

Finally, an innovation to the foreign real interest rate, $\varepsilon_{\rho^{*}, t}$, generates a real depreciation that lasts for nearly ten months (Figure 8). As a result of this, output increases and, in turn, inflation rises in an important and persistent way. The central bank reaction is to increase the interest rate. Again, this pattern is quite consistent with Parrado's (2001) IRF derived from a structural VAR.

The structural model estimated for Chile in this paper reflects quite well the dynamic of the economy when faced to different shocks. In particular, in the face of a monetary policy innovation, the model generates a dynamic which is consistent with that found in an unrestricted VAR. On the other hand, in the face of the other domestic shocks, responses are as expected and, do coincide with those found for 
Chile in Valdes (1997). In the case of foreign innovations, in particular country risk and foreign interest rate, the dynamic responses follow a similar pattern to those derived from a structural VAR in Parrado (2001).

\section{FIGURE 6}

STRUCTURAL MODEL: RESPONSES TO A ONE SD REAL EXCHANGE RATE SHOCK (Percentage change)
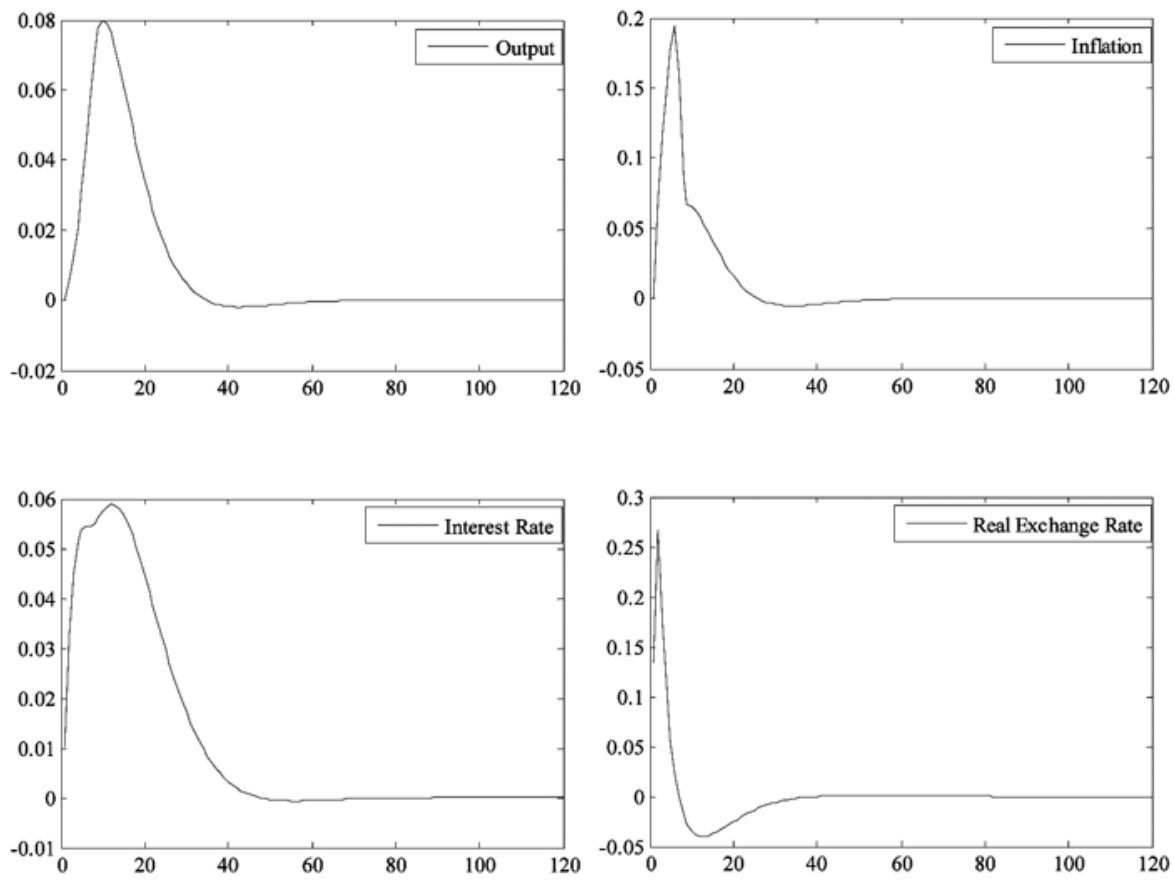

Now, with this model at hand, it is possible to analyze the welfare implications of alternative policy reaction functions. In particular, given the history of structural shocks, we can analyze what are the advantages, and costs, of adopting a policy reaction function, like (9), that reacts to exchange rate fluctuations. This analysis can be performed for the combination of all innovations and for each shock in particular. Before performing this analysis, the next section describes the structural innovations that the Chilean economy faced in the last decade. 


\section{FIGURE 7}

STRUCTURAL MODEL: RESPONSES TO A ONE SD FOREIGN OUTPUT SHOCK

(Percentage change)


\section{STRUCTURAL SHOCKS}

In the nineties, besides facing domestic innovations, the Chilean economy was subject to several external shocks. In fact, the world economy was hit by several crisis in this period: to the Mexican 1995 exchange rate collapse it followed the Asian crisis in July 1997, the Russian crisis in August 1998, and the near-collapse of the U.S. hedge fund Long-Term Capital Management (LTCM) in September 1998. As Keating (1992) and Parrado (2001) make it clear, in an unrestricted VAR it is difficult to identify the structural innovations, domestic and external. In a VAR framework, some innovations may contain linear combination of the structural shocks and hence, their interpretation may become meaningless. The advantage of the structural model, estimated in this paper, is that domestic and external shocks are fully identified. In fact, the residual series in each equation can be interpreted as a structural innovation and, therefore, it is possible to assess the relative contribution of each shock to the overall volatility in the economy. 


\section{FIGURE 8}

STRUCTURAL MODEL: RESPONSES TO A ONE SD FOREIGN INTEREST RATE SHOCK (Percentage change)


The path followed by domestic shocks is presented in Figure 9. Aggregate demand innovations reflect the expansionary cycles of the early and mid nineties. The relative size of those innovations is, however, small. In the case of aggregate supply innovations, they exhibit a high volatility in the first half of the sample, 1990.09-1994.12, that decreased considerably in the late nineties. One interpretation to this fact has to do with the credibility of the inflation target. In fact, before 1994 the target was a twodigit number and, when a one-digit target was set and achieved on December 1994, the targeting regime gained confidence. As a result, supply shocks generated less persistent effects on inflation.

The term premium and monetary policy innovations followed a random pattern. However, in September 1998 there is a significant increase in both the long-term and policy interest rate. This increase is particularly important in the case of the monetary policy interest rate and, has been interpreted (see Landerretche, Morandé and Schmidt-Hebbel (2000)) as a policy response to external shocks. In the case of Chile those external innovations are presented in Figure 10. It is evident that the country risk premium experienced a significant increase in September 1998. According 
to Dungey et al. (2002), this increase, observed also in developed countries, is the consequence of higher risk aversion in international market participants as a result of the Russian crisis and LTCM near-collapse in August-September 1998. This increase in risk premium is not present in Chile in other financial crisis, like Mexico 1995, and is evidence that the spillover effects were limited in that occasion. It is worth noting that the country risk innovations do not increase permanently after September 1998. Dungey et al. (2002) concluded that the FED aggressive easing of monetary policy in that period may have contributed to reduce the duration of such crisis. Consistent with this fact, the foreign interest rate innovations in Figure 10 present a contraction in the period August to November 1998.

\section{FIGURE 9}

DOMESTIC STRUCTURAL SHOCKS (1990-2000)

(Monthly frequency)
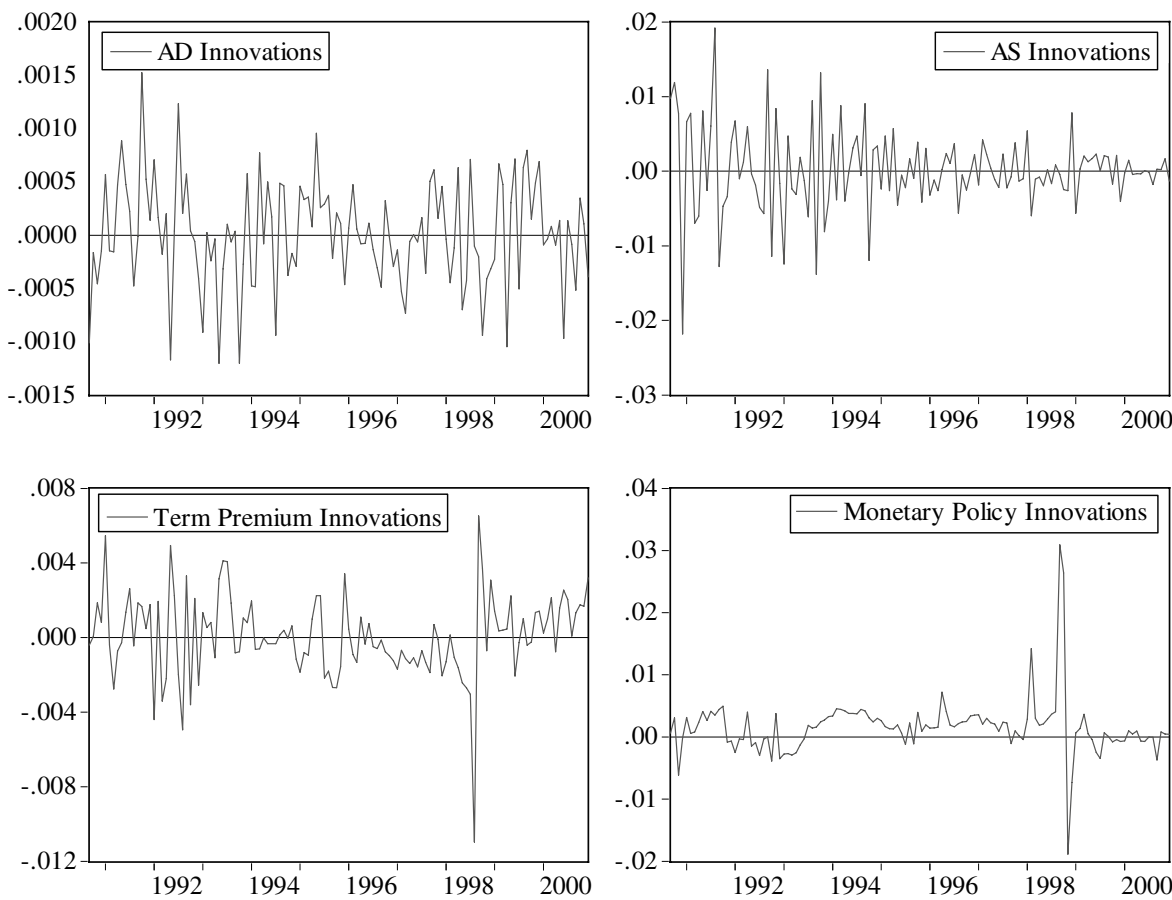


\section{FIGURE 10}

FOREING STRUCTURAL SHOCKS (1990-2000)

(Monthly frequency)
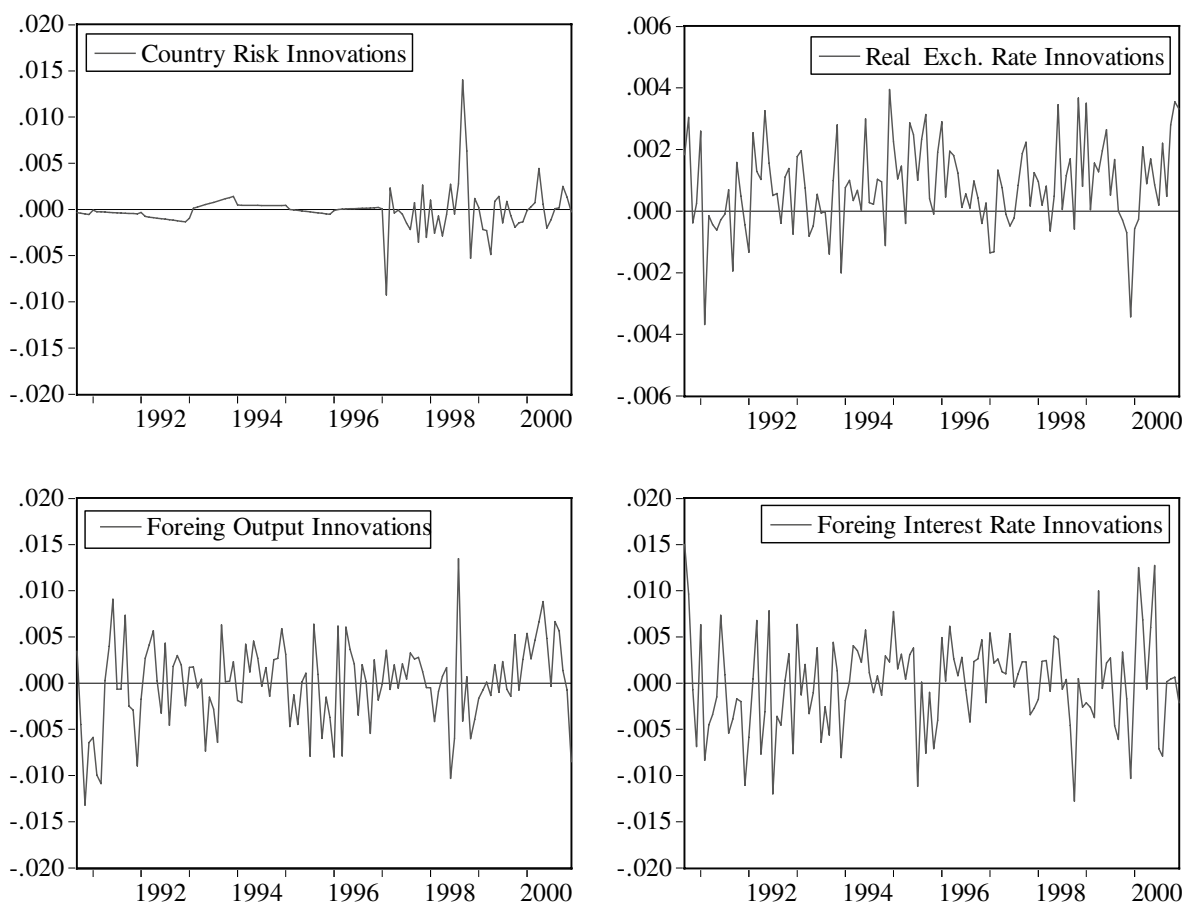

On the other hand, real exchange rate innovations follow a random path. However, they show a period of expansion in 1997 and 1998, and an important contraction at the end of 1999. Finally, foreign output shocks present an increase in September 1998 and, also, in the period 1999 to 2000 before the US recession that followed.

When compared to the rest of the innovations, the volatility of aggregate demand shocks is small and does not change over time. On the contrary, aggregate supply innovations present the highest level volatility in the early nineties which decreases later on. The term premium innovation volatility is constant over samples, whereas the monetary policy innovations become more volatile in the late nineties.

In terms of external shocks, the country risk premium shows a dramatic change: in the early nineties its volatility was just a fraction of the volatility experienced in the late nineties. The variance of the other external shocks slightly decreases. However, relative to the volatility of aggregate supply innovations, external shocks become more important. 


\section{PERFORMANCE OF ALTERNATIVE MONETARY POLICY RULES}

In this section we assess whether responding to exchange rate fluctuations does generate welfare gains. Following Leitemo and Sodestrom (2005), Batini, Harrison and Millard (2003) and Caputo (2004) we first specify a welfare loss criterion that penalizes inflation, output and interest rate volatility. This criterion can be described as

$$
L=2 \sigma_{\pi}^{2}+\sigma_{y}^{2}+0.5 \sigma_{r}^{2}
$$

which is an inflation targeting loss criterion that penalizes, mainly, inflation volatility.

In the first exercise, the loss criterion in (13) is computed assuming the central bank sets interest rates according to equation (9). In this case, the policy response to real exchange rate misalignments, denoted as $\rho_{q}$, is $\rho_{q}=0.633$. Then, we set $\rho_{q}$ to zero ${ }^{12}$ and recomputed the loss criterion in (13). This exercise is performed for individual shocks and for the combination of them. The results are presented in Table 2.

\section{TABLE 2}

CHILE: WELFARE LOSS UNDER ALTERNATIVE POLICY RULES

(Full Sample: 1990.09-2000.12)

\begin{tabular}{|lccc|}
\hline Shock & Loss for $\rho_{q}=0$ & Loss for $\rho_{q}=0.633$ & Difference (\%) \\
\hline Aggregate demand & 0.02 & 0.02 & $18.1 \%$ \\
Aggregate supply & 0.61 & 0.61 & $0.0 \%$ \\
Term premium & 0.00 & 0.00 & $40.8 \%$ \\
Monetary policy & 1.48 & 1.39 & $-6.2 \%$ \\
Country risk premium & 0.48 & 0.44 & $-9.3 \%$ \\
Real exchange rate & 0.44 & 0.42 & $-6.3 \%$ \\
Foreign output & 0.07 & 0.08 & $17.7 \%$ \\
Foreign interest rate & 2.87 & 2.72 & $-5.2 \%$ \\
\hline Total Loss & 4.72 & 4.50 & $-4.6 \%$ \\
\hline
\end{tabular}

According to the results, adopting a policy rule like the one in equation (9) reduces welfare losses by $4.6 \%$, well above the gains reported in Leitemo and Sodestrom (2005) and Caputo (2004). This order of magnitude corresponds to what Alexandre, Driffil and Spagnolo (2002) denote substantial gains.

12 The response to output and expected inflation is not modified. 


\subsection{Performance to Domestic Innovations}

For most domestic innovations (the exemption being monetary policy shocks), responding to real exchange rate misalignments increases welfare losses. In fact, the welfare loss increases in the case of aggregate demand and term premium shocks and it remains unchanged for aggregate supply innovations. To understand why the performance to aggregate demand innovations is poor, Figure 11 shows the dynamic response of the main variables under two policy rules.

\section{FIGURE 11}

ALTERNATIVE RESPONSES TO A ONE SD AGGREGATE DEMAND SHOCK

(Solid line, $\rho_{q}=0.633$, dotted line $\rho_{q}=0$, percentage change)
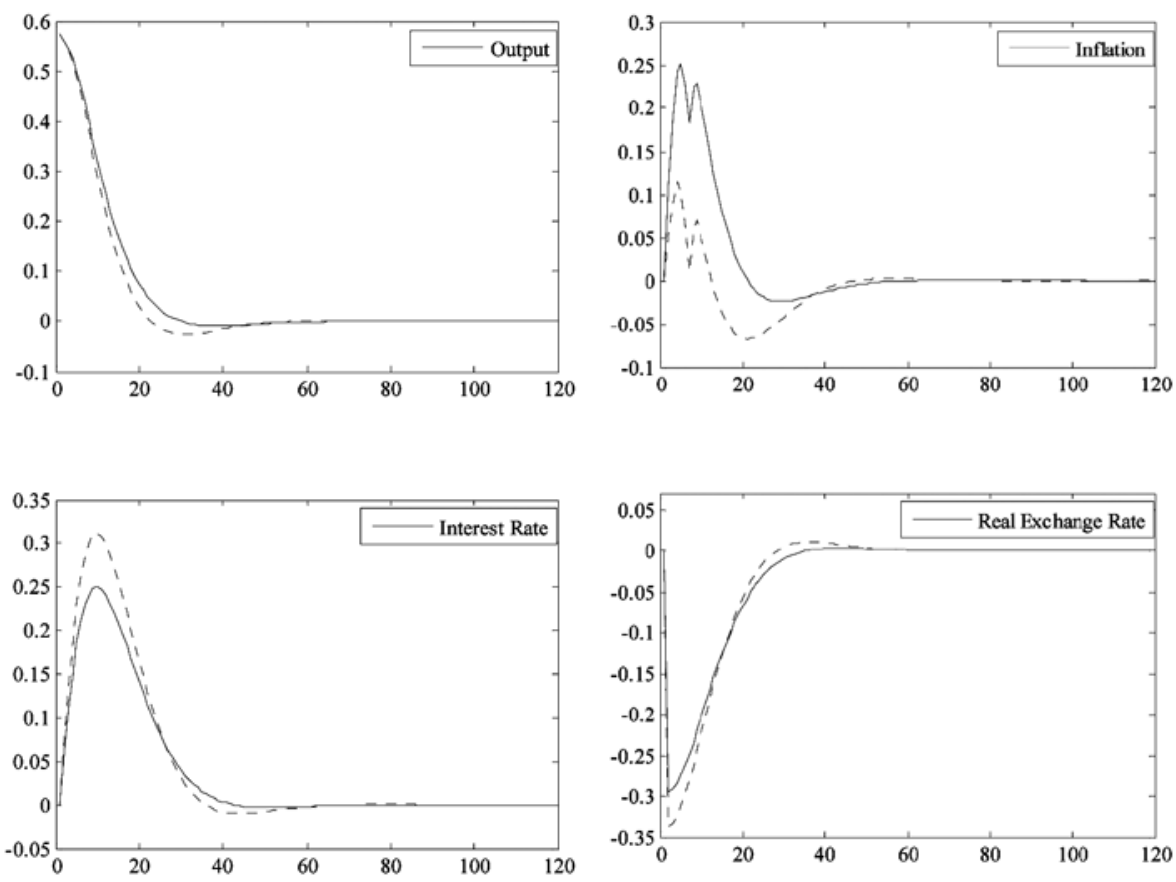

In the baseline scenario, $\rho_{q}=0.633$, an aggregate demand shock generates an increase in the interest rate (solid line Figure 11). This increase is, however, less important than the one in the alternative scenario $\left(\rho_{q}=0\right)$. The reason is that, when $\rho_{q}=0.633$, the central bank reduces the initial exchange rate appreciation by keeping a lower interest rate. As a result, output does not contract as much and the real exchange rate appreciation is also lower. Those two factors explain why inflation increases more 
when $\rho_{q}=0.633$. Therefore, responding to exchange rate misalignments attenuates the volatility of interest rates and the real exchange rate in the face of aggregate demand shocks. This comes, however, at the cost of inducing higher output and inflation volatility increasing, eventually, the welfare losses.

On the other hand, when the economy faces a monetary policy innovation, reacting to exchange rate brings welfare gains. The reason can be understood by analyzing the dynamic responses to a policy shock in Figure 12. In this case, an interest rate shock generates a real appreciation and a contraction in output. Now, when $\rho_{q}=0.633$, the central bank reduces its interest rate more aggressively in order to stabilize the exchange rate (solid line in Figure 12). Consequently, output, exchange rate and interest rate volatility goes down and, as a result, the total welfare loss is reduced. ${ }^{13}$

\section{FIGURE 12}

ALTERNATIVE RESPONSES TO A ONE SD DOMESTIC INTEREST RATE SHOCK (Solid line, $\rho_{q}=0.633$, dotted line $\rho_{q}=0$, percentage change)


13 In this case there is a marginal increase in inflation volatility. 


\subsection{Performance to External Innovations}

For most external shocks a policy rule like (9) brings welfare gains. In fact, in the face of real exchange rate, country risk, and foreign interest rate innovations responding to exchange rate misalignments generates a more stable path for the real exchange rate, which in turn, reduces the volatility of output and inflation. Those welfare gains come at the cost of inducing a higher interest rate volatility that is, however, not strongly penalized by the loss criterion in equation (13).

To understand the dynamic behind the previous results, it is useful to analyze the impulse response functions to a country risk innovation in Figure 13. ${ }^{14}$ This innovation depreciates the real exchange rate increasing both output and inflation.

\section{FIGURE 13}

\section{ALTERNATIVE RESPONSES TO A ONE SD AGGREGATE DEMAND SHOCK}

(Solid line, $\rho_{q}=0.633$, dotted line $\rho_{q}=0$, percentage change)
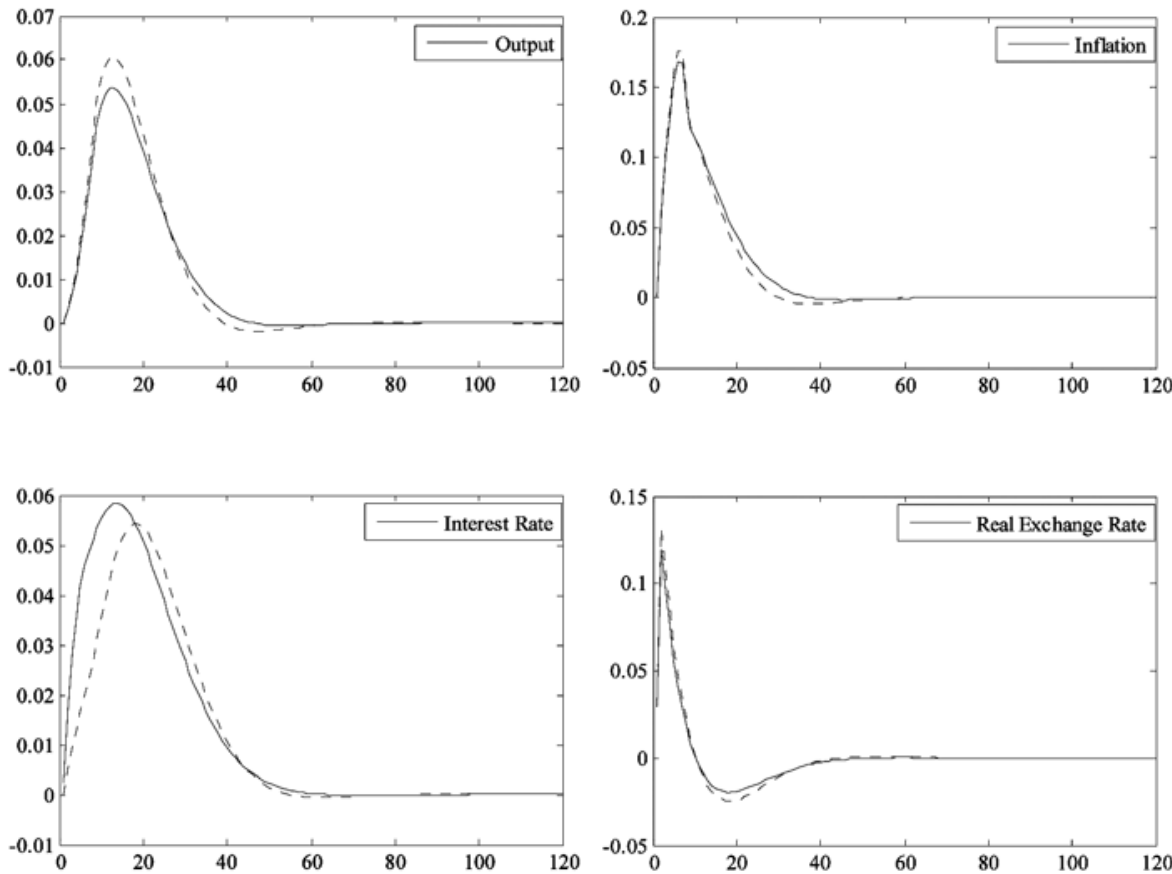

14 The dynamic response to the other external shocks, foreign interest rate and real exchange rate, is similar to that presented in Figure 13. Hence, for brevity, we do not include a graphical analysis of those shocks. 
In the case in which the central bank reacts to real exchange rate misalignments, solid line in Figure 13, the interest rate increases by more, attenuating the real depreciation and the subsequent expansion of output and inflation. Hence, a policy reaction function like (9) attenuates output and inflation volatility, ${ }^{15}$ reducing the welfare loss associated to a country risk shock. The same result holds for exchange rate and foreign interest rate innovations.

Overall, responding to real exchange rate misalignments reduces the impact that external shocks have on output and inflation. In particular, such a response generates a more stable path for the real exchange rate that induces a lower volatility in both output and inflation. In consequence, the welfare losses are reduced.

Finally, a more general result in this section is that responding to exchange rate misalignments brings welfare benefits, even though exchange rate volatility does not enter per se into the welfare loss criterion (13).

\section{EXTERNAL VOLATILITY AND THE ROLE OF THE EXCHANGE RATE}

The results presented so far suggest that there are welfare gains from responding to real exchange rate misalignments. Those gains are particularly important when the economy is subject to external shocks: country risk premium, foreign interest rate and exchange rate innovations. Given the recent episodes of high volatility in the country risk premium (see Figure 10), it is interesting to analyze whether the advantages from responding to exchange rate misalignments are somehow determined by the volatility of the external (and perhaps domestic) innovations. In this section, we investigate this issue in three stages. First, we assess the performance of policy rules in sub-samples with different volatility of innovations. Second, we illustrate how the policy reaction to exchange rate, $\rho_{q}$, may change in the presence of more volatile innovations. Finally, we test whether the central bank reacted, indeed, differently to different external innovations and the consequences of this on welfare.

\subsection{Sub-sample Analysis}

A visual inspection of Figures 9 and 10, reveals an apparent shift in the volatility of some structural shocks. In particular, it seems that supply shocks are more stable in the late nineties whereas, in the same period, country risk and domestic interest rate shocks appear to be more volatile. In this subsection, we analyze whether this apparent shift in volatility is significant and the implications that it may have on the performance of alternative monetary policy rules.

To provide a more formal analysis of the apparent shift in volatility, we proceed as in McConnell and Perez-Quiros (2000) and test whether the volatility of each shock has experienced a structural break. In particular, for each of the $i$ elements in the vector of estimated innovations, $\varepsilon_{t}$, we estimate the following equation

15 Interest rate volatility increases. This does not offset the gains from a lower deviation in inflation and output. 


$$
\sqrt{\frac{\pi}{2}}\left|\varepsilon_{i, t}\right|=\alpha_{1} D_{1, t}+\alpha_{2} D_{2, t}+\mu_{t}
$$

where, as noted by McConnell and Perez-Quiros (2000), $\sqrt{\frac{\pi}{2}}\left|\varepsilon_{i, t}\right|$ is an unbiased estimator of the standard deviation of $\varepsilon_{i, t}$. On the other hand, the dummy variables $D_{1, t}$ and $D_{2, t}$ are defined as

$$
D_{1, t}=\left\{\begin{array}{l}
1 \text { if } t \leq T \\
0 \text { if } t>T
\end{array} \text { and } \quad D_{2, t}=\left\{\begin{array}{l}
0 \text { if } t \leq T \\
1 \text { if } t>T
\end{array}\right.\right.
$$

and $T$ is the break point date. In this context, if $\alpha_{1}=\alpha_{2}$ we reject the hypothesis that innovations have experienced a volatility shift. We estimate equation (14) for two break point dates, $T=1994.12$ that reflects the moment in which the volatility of inflations shocks begin to decline and $T=1996.12$ that marks the beginning of more volatile country risk innovations. For both dates results are similar. However, for $T=1996.12$ the change in risk premium and domestic interest rate innovations is more important. Hence, since we are interested in analyzing the role of $\rho_{q}$ in a more volatile external environment, we only present the results for $T=1996.12 .16$

\section{TABLE 3}

VOLATILITY OF STRUCTURAL SHOCKS

(Standard deviation in \%)

\begin{tabular}{|lcccc|}
\hline \multicolumn{1}{|c}{ Shock } & $\begin{array}{c}\text { Full Sample } \\
(1990.09-2000.12)\end{array}$ & $\begin{array}{c}\text { Early Nineties } \\
(1990.09-1996.12)\end{array}$ & $\begin{array}{c}\text { Late Nineties } \\
(1997.01-2000.12)\end{array}$ & $\begin{array}{c}t \text {-test } \\
\left(H_{0}: \alpha_{1}=\alpha_{2}\right)\end{array}$ \\
\hline Aggregate demand & 0.57 & 0.58 & 0.58 & 0.08 \\
Aggregate supply & 6.98 & 8.63 & 3.14 & $25.4^{* *}$ \\
Term premium & 0.22 & 0.21 & 0.25 & 0.17 \\
Monetary policy & 0.47 & 0.25 & 0.70 & $1.5^{*}$ \\
Country risk premium & 0.21 & 0.06 & 0.33 & $29.3^{*}$ \\
Real exchange rate & 1.62 & 1.63 & 1.63 & 0.05 \\
Foreign output & 5.55 & 5.71 & 5.19 & 1.23 \\
Foreign interest rate & 0.51 & 0.52 & 0.50 & 0.43 \\
\hline
\end{tabular}

$* * H_{0}: \alpha_{1}=\alpha_{2}$ rejected at $99 \%$.

$* H_{0}: \alpha_{1}=\alpha_{2}$ rejected at $80 \%$.

16 The results, in terms of the performance of alternative policy rules in different samples do not depend on $T$. 
The above results confirm, for standard confidence levels, a shift in the volatility of supply and country risk innovations. In particular, in the sub-sample 1996.12 to 2000.12 , inflation innovations become less volatile while country risk shocks increase their variance substantially. For less conventional confidence levels $(80 \%)$, monetary policy innovations become, also, more volatile in this sub-sample.

In terms of the general performance of alternative policy rules, a volatility shift does not change the main conclusions derived in previous sections: reacting to exchange rate misalignments generates welfare gains. In fact, in the early and late nineties responding to exchange rate misalignments reduces welfare losses by $-4.6 \%$ and $-3.5 \%$ respectively (see Table 4 and 5 ).

The volatility shift affects, however, the total loss associated to particular shocks and the relative advantage of responding to exchange rate misalignments. In fact, when country risk innovations are more volatile the welfare loss associated to this shock increases from 0.34 (Table 4) to 0.59 (Table 5). For this same shock, the relative advantage ${ }^{17}$ of reacting to exchange rate increases from $-5.2 \%$ in the early nineties (Table 4) to $-12.9 \%$ in the late nineties (Table 5). An increase in monetary policy innovations also increases the welfare losses associated to this shock, from 0.96 to 1.72 , and the relative advantage of responding to exchange rate, from $-8.5 \%$ to $-10.9 \%$. Finally, a lower degree of volatility in inflation innovations reduces the welfare losses from 0.87 to 0.20 .

TABLE 4

WELFARE LOSS FOR ALTERNATIVE POLICY RULES

(1990.09-1996.12)

\begin{tabular}{|lccc|}
\hline \multicolumn{1}{|c}{ Shock } & Loss for $\rho_{q}=0$ & Loss for $\rho_{q}=0.633$ & Difference (\%) \\
\hline Aggregate demand & 0.02 & 0.02 & $18.3 \%$ \\
Aggregate supply & 0.87 & 0.87 & $0.0 \%$ \\
Term premium & 0.00 & 0.00 & $35.0 \%$ \\
Monetary policy & 1.05 & 0.96 & $-8.5 \%$ \\
Country risk premium & 0.36 & 0.34 & $-5.2 \%$ \\
Real exchange rate & 0.43 & 0.44 & $1.2 \%$ \\
Foreign output & 0.06 & 0.07 & $20.1 \%$ \\
Foreign interest rate & 2.94 & 2.73 & $-7.3 \%$ \\
\hline Total Loss & 5.89 & 5.62 & $-4.6 \%$ \\
\hline
\end{tabular}

17 This advantege is the measured as the reduction in welfare losses. 


\section{TABLE 5}

WELFARE LOSS FOR ALTERNATIVE POLICY RULES

(1997.01-2000.12)

\begin{tabular}{|lccc|}
\hline \multicolumn{1}{|c}{ Shock } & Loss for $\rho_{q}=0$ & Loss for $\rho_{q}=0.633$ & Difference (\%) \\
\hline Aggregate demand & 0.02 & 0.02 & $17.1 \%$ \\
Aggregate supply & 0.20 & 0.20 & $0.0 \%$ \\
Term premium & 0.00 & 0.00 & $41.3 \%$ \\
Monetary policy & 1.93 & 1.72 & $-10.9 \%$ \\
Country risk premium & 0.68 & 0.59 & $-12.9 \%$ \\
Real exchange rate & 0.46 & 0.38 & $-16.1 \%$ \\
Foreign output & 0.06 & 0.07 & $19.8 \%$ \\
Foreign interest rate & 1.43 & 1.26 & $-11.6 \%$ \\
\hline Total Loss & 2.44 & 2.36 & $-3.5 \%$ \\
\hline
\end{tabular}

\subsection{Risk Premium and Nonlinear Response to Real Exchange Rate}

One feature of the Chilean monetary policy, reported in Caputo (2005), is that there is an nonlinear policy response to exchange rate misalignments: the central bank reacts more strongly to large real exchange rate misalignments. In this context, a natural question emerges: is it desirable to react more strongly to exchange rate when external innovations become more volatile? The previous results seem to support this view. In fact, it is concluded that the relative advantages of a positive response to exchange rate, $\rho_{q}=0.633$, increase with the volatility of country risk innovations. However, in the previous exercise the $\rho_{q}$ coefficient is kept constant across samples. Hence, it is not possible to conclude that it is optimal to increase $\rho_{q}$ when external volatility rises.

In order to determine whether it is optimal to increase $\rho_{q}$ when innovations become more volatile, we perform a counter-factual exercise. Given the history of shocks, we induce more volatility in some specific innovations. ${ }^{18}$ Then, we compute the value of $\rho_{q}$ that generates the same welfare loss than in the baseline scenario (no increase in volatility). This exercise considers two of the innovations that experienced a significant shift in volatility: country risk premium innovations, $\varepsilon_{\text {Risk }, t}$, and monetary policy innovations, $\varepsilon_{\rho, t}$. We also consider innovations with no volatility shifts, but with a direct impact on exchange rate: real exchange rate, $\varepsilon_{q, t}$, and foreign interest rate innovations, $\varepsilon_{\rho^{*}, t}$. Table 6 reports the values of $\rho_{q}$ in each scenario. For comparison purposes it is useful to remember that, originally, $\rho_{q}=0.6331$.

18 The volatility is increased by $20 \%$. In each case, just one series of innovations is modified. The remaining series are set to their historical levels. 
TABLE 6

COUNTER-FACTUAL EXCHANGE RATE REACTION COEFFICIENTS

\begin{tabular}{|lc|}
\hline Increased Volatility in & Counter-factual value of $\rho_{q}$ \\
\hline Country Risk Innovation & 2.31 \\
Monetary Policy Innovation & 4.87 \\
Real Exchange Rate Innovation & 1.14 \\
Foreign Interest Rate Innovation & 2.89 \\
\hline
\end{tabular}

The above results show a significant departure of $\rho_{q}$, from its original level. In particular, when country risk and monetary policy innovations (domestic and foreign) become more volatile it is desirable to react more strongly to exchange rate misalignments. On the other hand, a more modest increase in $\rho_{q}$ is observed in the case of more volatile exchange rate innovations.

The evidence presented so far provides some understanding of why a nonlinear response to exchange rate, like the one observed in Chile, may emerge. In fact, reacting more strongly to large exchange rate misalignments, induced by larger and more volatile shocks to interest rate and country risk premiums, is optimal: such nonlinear response contributes to the stabilization of output and inflation while increasing interest rate volatility.

To illustrate the above argument, Table 7 presents the relative performance of two policy rules when country risk innovations are more volatile ${ }^{19}$ and the rest of the shocks are set to the historical levels. In the first policy rule $\rho_{q}=0.633$ whereas in the second one the exchange rate response is the counter-factual value of $\rho_{q}=2.305$. It is clear that the benefits, in terms of the reduction in output and inflation variance, dominate the costs associated to a more volatile interest rate. Overall, a stronger response to exchange rate reduces welfare losses by $10.1 \%$.

\section{TABLE 7}

TOTAL LOSSES FOR AN ALL SHOCK SCENARIO

(standard deviation of $\varepsilon_{\text {Risk,t }}$ is increased by 20\%)

\begin{tabular}{|lccc|}
\hline & $\rho_{q}=2.305$ & $\rho_{q}=0.633$ & Difference \\
\hline Inflation Variance & 1.57 & 1.88 & $-37.3 \%$ \\
Output Variance & 0.10 & 0.16 & $-16.3 \%$ \\
Interest Rate Variance & 2.53 & 2.20 & $15.2 \%$ \\
\hline Total Welfare Loss & 4.50 & 5.01 & $-10.1 \%$ \\
\hline
\end{tabular}

19 The conclusions hold for the rest of the innovations in Table 6. 


\subsection{Testing Nonlinear Response to Real Exchange Rate Components}

The previous two exercises illustrate how monetary policy may have reacted in a more volatile environment. It is concluded that, responding to exchange rate is optimal independently of the volatility of some external and internal innovations. Furthermore, when the volatility of those innovations increases, a stronger response to exchange rate is desirable.

In this sub-section we test how the Chilean central bank did react, in practice, to different innovations. To perform this analysis, we substitute the exchange rate equation (4) into the policy reaction function, equation (9). We then estimate explicit policy responses to the various observable innovations to the exchange rate equation. The modified policy reaction function is

$$
\begin{aligned}
\rho_{t}=0.878 \rho_{t-1}+0.112 & {\left[0.786 E_{t}\left(\pi_{t+15}\right)+1.122 y_{t-1}+0.633\left(g_{0} E_{t}\left(q_{t+1}\right)\right.\right.} \\
& \left.\left.+g_{1}\left(\rho_{t}^{*}-\rho_{t}\right)+g_{2} \text { Risk }_{t}\right)\right]
\end{aligned}
$$

were $g_{0}, g_{1}$ and $g_{2}$ capture the response of the central bank to each component of the real exchange rate. If those responses are consistent with a uniform response to the exchange rate aggregator, then $g_{0}=1, g_{1}=d_{1}=1.082$ and $g_{2}=d_{2}=2.354$. As in Caputo (2003a), we use GMM instrumental variables to estimate equation (15). The results are presented in the first column of Table 8.

\section{TABLE 8}

MONETARY POLICY RESPONSE TO RER COMPONENTS $a$

\begin{tabular}{|ccc|}
\hline Coefficients & Baseline Estimates & With Dummy 98.09-98.10 \\
\hline$g_{0}$ & $1.042^{* *}$ & $1.039^{* *}$ \\
& $(0.07)$ & $(0.07)$ \\
$g_{1}$ & $7.394^{* *}$ & $7.305^{* *}$ \\
& $(0.84)$ & $(0.82)$ \\
$g_{2}$ & $16.896^{* *}$ & $16.770^{* *}$ \\
& $(1.7)$ & $(1.62)$ \\
$g_{2}^{1}$ & - & $115.833^{* *}$ \\
& & $(6.52)$ \\
\hline
\end{tabular}

a GMM Instrumental Variables: uses the same instruments as in Caputo (2005).

$* *$ Significant at $99 \%$. 
The response to the expected real exchange rate, $g_{0}$, is not statistically different from one. ${ }^{20}$ However, $g_{1}$ and $g_{2}$ are considerably larger than $d_{1}$ and $d_{2}$ respectively. This suggests that, in the face of interest rate spread and country risk shocks, the response of the central bank was more aggressive than the uniform response to the exchange rate.

To see whether the above result may have been determined only by large external shocks, such as the increase in the country risk premium associated with the LTCM collapse and the Russian financial crisis, we reestimate equation (5) including a multiplicative dummy ${ }^{21}$ for the country risk variable. The results, presented in the third column of Table 8, suggest that during the period September-October 1998 the policy response to the country risk premium, $g_{2}^{1}$, was much more aggressive than the response in the rest of the sample, $g_{2}$. On the other hand, the coefficients $g_{0}, g_{1}$ and $g_{2}$ do not change significantly from the baseline estimates.

The preceding result indicates that a more aggressive response to country risk was not determined by a single episode of higher external volatility 22 but was a more permanent feature of Chilean monetary policy. This result also indicates that, in response to the 1998 increase in the risk premium, the Chilean central bank deviated substantially from its historical reaction to this type of shock.

In this context, some authors, like Taylor (2001), have suggested that policy rules with an aggressive response to the exchange rate may induce additional volatility in the economy. In consequence, those rules may generate a worse performance. To see whether this is the case in Chile, we analyze the welfare implications of responding more aggressively to country risk and interest rate spread shocks. In particular, we compare the performance of a policy rule with a uniform response to the exchange rate, equation (9), with a policy rule that allows for differentiated responses to each component of the exchange rate, equation (5). The results of such a comparison are presented in Table 9.

The results in Table 9 show that there are significant gains from adopting a more aggressive response to both interest rate spreads and country risk shocks. In fact, this type of response reduces, in an important way, the volatility of inflation and output. Moreover, this more aggressive policy rule changes only marginally the volatility of interest rates. The behavior of the Chilean central bank is fully consistent with the results presented in Table 9. In that case, it was concluded that a more aggressive policy response to country risk premium and domestic and external interest rates shocks was desirable if the volatility of such variables increases (which is the case for Chile in the late nineties, see Table 3).

20 The $H_{0}: g_{0}=1$ cannot be rejected at $95 \%$ confidence interval.

21 The dummy variable, $d u m=1$ in 1998.09 and 1998.10 and it is zero in all other dates. Then, the response to country risk can be expressed as $(1-d u m) g_{2}+d u m g_{2}^{1}$. In this case, the total response to country risk in 1998.09 and 1998.10 is captured by $g_{2}^{1}$.

22 This result is robust to a more extended sample for the dummy variable. In fact, if the dummy is extended for an additional five months, the estimated value of $g_{2}$ does not change significantly. 


\section{TABLE 9}

TOTAL LOSSES FOR AN ALL SHOCK SCENARIO

\begin{tabular}{|lccc|}
\hline & Equation (15) & Equation (9) & Difference \\
\hline Inflation Variance, $\sigma_{\pi}^{2}$ & 1.448 & 1.661 & $-13.7 \%$ \\
Output Variance, $\sigma_{y}^{2}$ & 0.108 & 0.125 & $-12.8 \%$ \\
Interest Rate Variance, $\sigma_{r}^{2}$ & 2.098 & 2.112 & $-0.7 \%$ \\
\hline Total Welfare Loss (all shocks) & 4.053 & 4.503 & $-10.00 \%$ \\
\hline
\end{tabular}

Equation (9): $g_{0}=1, g_{1}=d_{1}=1.082$ and $g_{2}=d_{2}=2.354$.

Equation (15): $g_{0}=1.402, g_{1}=7.394$ and $g_{2}=16.896$.

Now, there is evidence that in some particular episodes, the LTCM collapse and the Russian financial crisis in 1998, the response to country risk shocks was even more aggressive. In fact, as shown in Table 8, in that particular episode, the central bank's reaction to country risk increased from $g_{2}=16.896$ to $g_{2}^{1}=115.833$. Many analysts have criticized this type of reaction on the grounds that it can exacerbate the volatility of the macroeconomic variables without generating any welfare benefit. In particular, Jonas and Mishkin (2003) call this focus on the exchange rate a serious "policy mistake". In order to see whether this episodic response was indeed destabilizing, we assess the performance of two policy rules. The first one does not contain an episodic response to country risk shocks and hence, $g_{2}=16.896$ in the whole sample (see Table 8, second column). The second policy rule contains an episodic response, $g_{2}^{1}=115.833$ in the period September-October 1998, and also allows for a more moderate reaction in the rest of the sample, $g_{2}=16.770$ (see Table 8, third column). The results are presented in Table 10.

TABLE 10

TOTAL LOSSES FOR AN ALL SHOCK SCENARIO

(Equation with dummy)

\begin{tabular}{|lccc|}
\hline & Equation (15) & Equation (9) & Difference \\
\hline Inflation Variance, $\sigma_{\pi}^{2}$ & 1.455 & 1.448 & $0.5 \%$ \\
Output Variance, $\sigma_{y}^{2}$ & 0.105 & 0.108 & $-2.5 \%$ \\
Interest Rate Variance, $\sigma_{r}^{2}$ & 2.408 & 2.098 & $14.8 \%$ \\
\hline Total Welfare Loss (all shocks) & 4.219 & 4.053 & $4.1 \%$ \\
\hline
\end{tabular}

Equation (15): $g_{0}=1.402, g_{1}=7.394$ and $g_{2}=16.896$.

Equation (15): w/ dummy: $g_{0}=1.039, g_{1}=7.305, g_{2}=16.770$ and $g_{2}^{1}=115.833$. 
According to the results in Table 10, a much more aggressive policy reaction in the period September-October 1998 increases welfare losses by $4.1 \%$. In fact, such a reaction induces much more volatility in interest rates, an increase of $14.8 \%$, without reducing the variance of inflation that increases by $0.5 \%$. In this case, there is only a small gain in terms of output stability. 23

The previous subsections show that it is desirable to adopt an aggressive response to some of the components of the exchange rate. In this way, it is possible to reduce the volatility of output, inflation and interest rate. This result does not imply, however, that welfare will increase indefinitely if the central bank becomes even more aggressive. In fact, very large responses to external shocks can exacerbate the volatility of the main macro variables increasing welfare losses. Hence, a monetary policy overreaction to external shocks may be destabilizing.

\section{ROBUSTNESS EXERCISES}

The Chilean monetary policy rule, as described by equation (9), has a good performance in the face of the structural shocks that Chile faced in the nineties. This result is independent of the sample and, for an all shocks scenario, the gains from reacting to the exchange rate are important.

In this section, we test the robustness of our general results. In doing so, we perform three exercises. In the first one, we analyze the performance of the monetary policy rule, equation (9), to random disturbances rather than to the observed shocks. In the second exercise, we derive a policy reaction function that minimizes a criterion like (13) and see whether the exchange rate plays a role in such an optimal policy. Finally, we analyze the robustness of the results according to an alternative welfare loss criterion.

\subsection{Policy Performance in Response to Random Shocks}

Some of the shocks faced by the Chilean economy were not normally distributed and reflect, in some cases, specific events in which some variables, like interest rates and risk premium, deviated significantly from their average levels. ${ }^{24}$ Given the history of such shocks, the monetary policy rule in equation (9) performs well. In this context, a natural question is whether such a policy is still an efficient rule for a different configuration of shocks. In order to address this question, we assess the performance of alternative monetary policy rules in the face of random structural shocks. We perform three alternative exercises.

23 Output is more stable because, in the aggregate demand equations, the effects of a more stable exchange rate dominate the negative impacts of a more volatile interest rate. However, if output has a nonlinear reaction to the interest rate, this result may be reversed. In such a case, output will also be more volatile.

24 See notes in Table 1 indicating which of the shocks failed the normality test. 
In the first exercise, we investigate whether the previous result is robust to different assumptions about the way in which shocks are generated. In particular, we generate, for each element in the $\varepsilon_{t}$ vector, a series of normally distributed random shocks. ${ }^{25} \mathrm{We}$ set the variance of the shocks according to their historical level. On the other hand, we assume there is no covariance among shocks: in this exercise this covariance is set at zero. Then we compute the welfare criterion, equation (13), under the two alternative policy rules analyzed so far: one that contains the original exchange rate response, $\rho_{q}=0.633$ and another in which $\rho_{q}=0$. This sequence is repeated 100 times. The motivation for this exercise is that the observed comovement among structural shocks may be a transitory phenomenon and may not reflect a permanent feature of the Chilean economy. For instance, the high correlation between monetary policy and country risk shocks, observed in late 1998, reflects an unusually aggressive policy response to a very volatile external environment. The results, in terms of the welfare losses associated with each random shock, are presented in Table 11.

\section{TABLE 11}

WELFARE LOSS FOR RANDOM SHOCKS (NO SHOCK COVARIANCE)

(Historical variance of shocks and zero covariance)

\begin{tabular}{|lccc|}
\hline \multicolumn{1}{|c}{ Shock } & Loss for $\rho_{q}=0$ & Loss for $\rho_{q}=0.633$ & Difference (\%) \\
\hline Aggregate demand & 0.013 & 0.011 & $18.0 \%$ \\
Aggregate supply & 1.342 & 1.342 & $0.0 \%$ \\
Term premium & 0.000 & 0.000 & $29.7 \%$ \\
Monetary policy & 0.727 & 0.779 & $-6.7 \%$ \\
Country risk premium & 0.300 & 0.323 & $-7.0 \%$ \\
Real exchange rate & 0.280 & 0.289 & $-3.1 \%$ \\
Foreign output & 0.073 & 0.060 & $21.6 \%$ \\
Foreign interest rate & 1.958 & 2.032 & $-3.7 \%$ \\
\hline Total Loss (all shocks) & 2.261 & 2.325 & $-2.8 \%$ \\
\hline
\end{tabular}

In this exercise, a policy rule that reacts to the exchange rate performs well. In particular, as in the main results of Section 5, such a rule generates substantial gains in the face of most of the external shocks. In fact, for country risk, real exchange rate and foreign interest rate shocks that rule has a good performance. For monetary policy shocks, the performance is also good. On the other hand, as before, the performance is poor for the other domestic shocks.

25 Each random series contains 124 observations. This is consistent with the number of observations in the original estimation sample, 1990.09 to 2000.12 . For larger random samples of 1,$240 ; 12,400$ or more observations the results do not change. 
In the second exercise, we assume that the variances and covariances of the random shocks are set according to their historical level. In this way, the random shocks have similar properties to the estimated shocks. In this setup, we can assess whether the covariance among shocks explains the relative performance of a policy rule that reacts to the exchange rate. As before, we generate, for each element in the $\varepsilon_{t}$ vector, a series of normally distributed random shocks. The results, in terms of the welfare losses associated with each random shock, are presented in Table 12.

\section{TABLE 12}

WELFARE LOSS FOR RANDOM SHOCKS (HISTORICAL SHOCK COVARIANCE)

(Historical shocks' variance and covariance)

\begin{tabular}{|lccc|}
\hline \multicolumn{1}{|c}{ Shock } & Loss for & Loss for & Difference $(\%)$ \\
\hline Aggregate demand & 0.012 & 0.010 & $18.4 \%$ \\
Aggregate supply & 1.309 & 1.309 & $0.0 \%$ \\
Term premium & 0.000 & 0.000 & $29.5 \%$ \\
Monetary policy & 0.793 & 0.848 & $-6.5 \%$ \\
Country risk premium & 0.398 & 0.418 & $-4.7 \%$ \\
Real exchange rate & 0.246 & 0.262 & $-6.1 \%$ \\
Foreign output & 0.069 & 0.056 & $22.3 \%$ \\
Foreign interest rate & 1.534 & 1.618 & $-5.2 \%$ \\
\hline Total Loss (all shocks) & 2.266 & 2.356 & $-3.8 \%$ \\
\hline
\end{tabular}

In this scenario, a policy rule that reacts to the exchange rate performs well. The simulations presented here show that, if the relative size and comovements of shocks are kept at their historical levels, a policy reaction function like (9) will perform well. Furthermore, when the comovements are considered, the performance of such a rule improves (compare results in Table 11 and Table 12). This indicates that, besides the size of the shocks, their covariance is also an important element determining the advantages of responding to the exchange rate.

The last exercise considers a situation in which the shocks' covariance is set at zero and where all shocks have the same variance of $1 \%$. This means that some of the shocks for which the policy reaction function (9) has bad performance, like aggregate demand shocks, will increase their relative contribution to the total loss. On the other hand, some shocks for which the policy performance is good, like exchange rate shocks, will diminish their relative contribution. Finally, some shocks for which the policy performance is good, like country risk and monetary policy shocks, will increase their relative contribution to the total loss. In this exercise, increasing the policy response to the exchange rate from $\rho_{q}=0$ to $\rho_{q}=0.633$ reduces the total welfare loss from 12.792 to 12.291 (a percentage reduction in welfare losses of $3.9 \%$ ). On the other hand, the relative performance in response to individual shocks is the same as the one presented in Table 11 (last column). 
As in all previous exercises, a monetary policy rule that reacts to exchange rate misalignments has a good performance. Overall, independently of the size and comovement of the structural shocks, adopting a monetary policy rule that allows for a response to the exchange rate improves welfare if shocks are generated randomly.

\subsection{Optimal Policy Reaction Function}

The policy rule that has been assessed so far is the estimated reaction function for Chile in equation (9). This policy rule generates welfare gains and, therefore, is more efficient than a rule that sets $\rho_{q}=0$ and keeps the rest of the coefficients unchanged. The previous result does not necessarily imply, however, that such a rule is the optimal one given the welfare criterion in (13) and the history of shocks. In other words, it is possible that another rule, with different coefficients, does perform better. Furthermore, we have not ruled out the possibility that an optimal policy rule is one in which $\rho_{q}=0$. To address this issue, we perform a grid search to determine the optimal coefficients in the following IFB rule

$$
r_{t}=\rho r_{t-1}+(1-\rho)\left(\rho_{\pi} E_{t}\left(\pi_{t+15}\right)+\rho_{y} y_{t-1}+\rho_{q} q_{t}\right)
$$

we perform the grid search taking as given the historical series of structural shocks for Chile. The search procedure is the same as the one described in Caputo (2004). The optimal coefficients and the relative performance of two alternative policy rules are presented in Table 13.

TABLE 13

CHILE: OPTIMAL POLICY RULE COEFFICIENTS

\begin{tabular}{|lccccc|}
\hline \multicolumn{1}{|c}{ Policy Rule } & $\rho$ & $\rho_{\pi}$ & $\rho_{y}$ & $\rho_{q}$ & Total Loss \\
\hline R1: Rule with $\rho_{q}=0$ & 0.8 & 3.4 & 6.2 & 0.0 & 2.175 \\
R2: Rule with unrestricted $\rho_{q}$ & 0.8 & 3.4 & 5.9 & 0.8 & 2.139 \\
\hline
\end{tabular}

According to the above results, the optimal monetary policy reaction function contains a more aggressive response to output and expected inflation than the one observed in practice. In fact, the response to expected inflation increases from $\rho_{\pi}=0.79$ to $\rho_{\pi}=3.4$ whereas the response to output increases from $\rho_{y}=1.12$ to $\rho_{y}=5.9$. On the other hand, the optimal rule shows a high degree of interest rate persistence consistent with the observed monetary policy inertia in Chile. Finally, the optimal policy rule considers a response to exchange rate deviations and, as in equation (9), this response is comparatively less important than the policy reaction to expected inflation and output. The performance of the optimal rule is presented in Table 14. 
TABLE 14

WELFARE LOSS FOR THE OPTIMAL POLICY RULE

\begin{tabular}{|lccc|}
\hline \multicolumn{1}{|c}{ Shock } & Loss for $R I\left(\rho_{q}=0.0\right)$ & Loss for $R 2\left(\rho_{q}=0.8\right)$ & Difference $(\%)$ \\
\hline Aggregate demand & 0.143 & 0.100 & $-30.0 \%$ \\
Aggregate supply & 0.607 & 0.607 & $0.0 \%$ \\
Term premium & 0.000 & 0.000 & $-27.2 \%$ \\
Monetary policy & 0.469 & 0.389 & $-17.1 \%$ \\
Country risk premium & 0.119 & 0.103 & $-13.4 \%$ \\
Real exchange rate & 0.287 & 0.231 & $-19.4 \%$ \\
Foreign output & 0.315 & 0.219 & $-30.5 \%$ \\
Foreign interest rate & 0.464 & 0.470 & $1.2 \%$ \\
\hline Total Loss (all shocks) & 2.175 & 2.139 & $-1.7 \%$ \\
\hline
\end{tabular}

The optimal policy rule, $R 2$, has a good performance in the face of almost every single shock. The exception is the foreign interest rate shock for which the performance is marginally worst.

\subsection{Performance under an Alternative Welfare Criterion}

The welfare criterion used so far is an inflation targeting criterion that heavily penalizes inflation volatility. This criterion is not derived, explicitly, from the behavior of consumers and firms. Now, we analyze the performance of the monetary policy rule in (9) when an alternative loss criterion is used. In particular, as is shown in Caputo (2004), a utility-based welfare criterion penalizes, almost equally, consumption and domestic inflation volatility. This criterion also contains a negative weight on consumption autocovariance (i.e. higher consumption autocovariance reduces welfare losses). This criterion can be expressed as

$$
L_{1}=\sigma_{\pi}^{2}+\sigma_{y}^{2}-\sigma_{y, y}
$$

where the variances of domestic inflation and consumption are approximated by the variance of CPI inflation, $\sigma_{\pi}^{2}$, and output, $\sigma_{y}^{2}$, respectively. On the other hand, the consumption autocovariance is approximated by the autocovariance in output, $\sigma_{y, y}$.

The intuition behind the preceding result is that inflation volatility, $\sigma_{\pi}^{2}$, increases the expected disutility from labor, whereas the output variance, $\sigma_{y}^{2}$, reduces the expected utility of consumption. In consequence, $\sigma_{\pi}^{2}$ and $\sigma_{y}^{2}$, have a negative impact on welfare. On the other hand, an increase in the autocovariance in output, $\sigma_{y, y}$, tends to smooth the utility of consumption. In fact, when habits are present, the consumer's 
utility function is less volatile if current consumption and past consumption are highly correlated. Hence, a high value of $\sigma_{y, y}$ increases expected consumer's utility. ${ }^{26}$

Computing $L_{1}$ for alternative values of $\rho_{q}$ in the policy rule equation (9) shows that responding to the exchange rate is welfare improving, for the full sample and two sub-samples (Table 15).

TABLE 15

WELFARE LOSS FOR AN ALTERNATIVE WELFARE CRITERION

\begin{tabular}{|lccc|}
\hline \multicolumn{1}{|c}{ Sample } & $\rho_{q}=0.0$ & $\rho_{q}=0.633$ & Difference (\%) \\
\hline Full Sample & 1.771 & 1.633 & $-6.1 \%$ \\
Early Nineties & 2.415 & 2.275 & $-5.8 \%$ \\
Late Nineties & 0.657 & 0.619 & $-5.8 \%$ \\
\hline
\end{tabular}

Finally, when the optimal coefficients in Table 13 are considered, the results are the same: responding to the exchange rate, $\rho_{q}=0.8$, generates a reduction in the welfare loss criterion, $L_{1}$, of $-1.4 \%$.

\section{CONCLUSIONS}

In the context of the Chilean economy, a small open economy that pursues inflation targeting, this paper assesses the advantages of introducing exchange rate considerations into the monetary policy design. This question is relevant because, as reported by Schmidt-Hebbel and Tapia (2002) and Caputo (2005), the Chilean central bank does, indeed, react to exchange rate misalignments. Therefore, assessing the welfare implications of such responses is useful from a policymaking perspective.

In order to perform a welfare analysis, this paper estimates a small-scale macromodel and then it identifies the main sources of macroeconomic volatility. It is concluded that, external shocks were an important source of macroeconomic volatility in the nineties. In this context, a monetary policy rule that considers a response to the exchange rate brings important welfare gains. In fact, responding to exchange rate misalignments reduces the negative impacts that some external shocks have on output and inflation volatility. This reaction increases the variance of the policy instrument, but this effect does not dominate the welfare gains derived from a more stable path for inflation and output. In the face of some domestic shocks, reacting to exchange rate misalignments does not generate welfare gains. In particular, in the face of aggregate demand shocks, responding to the exchange rate exacerbates the volatility of output and inflation.

26 For a formal derivation of this result, see Caputo (2004). 
On the other hand, when the volatility of external shocks increases, it is optimal to respond more strongly to exchange rate misalignments. In fact, a more aggressive response to exchange rate misalignments offsets the negative implications, for output and inflation, of a more volatile external environment. In particular, the volatility of output and inflation is reduced with this more aggressive response to external disturbances that affect the real exchange rate. This latter result may explain why, in practice, it has been observed that the Chilean central bank reacts more strongly to larger exchange rate misalignments than to smaller ones. This result does not imply, however, that welfare will increase indefinitely if the central bank becomes even more aggressive. In fact, even larger responses to external shocks can exacerbate the volatility of the main macro variables, increasing welfare losses. Hence, a policy overreaction to external shocks may be destabilizing.

The main conclusions are robust to the sample period and the configuration of shocks. In particular, a monetary policy rule that responds to the exchange rate misalignments performs well in the face of normally distributed random shocks. In addition, the results are also robust to the use of an alternative welfare criterion. In fact, if an approximation to a utility-based welfare criterion is used, responding to exchange rate misalignments improves welfare.

Finally, the optimal policy reaction function is derived. It considers a response to output and inflation but also to the exchange rate. Furthermore, and consistent with empirical findings in Chile and elsewhere, the optimal policy response to the exchange rate is comparatively smaller than the response to output and inflation.

\section{REFERENCES}

ALEXANDRE, F.; J. DRIFFILL, and F. SPAGNOLO (2002). "Inflation Targeting, Exchange Rate Volatility, and International Policy Co-ordination", The Manchester School 70 (4), Special Issue, pp. 546-569.

ANDERSON, G. and G. MOORE (1985). "A Linear Algebraic Procedure for Solving Linear Perfect Foresight Models", Economic Letters 17, pp. 247-252.

BATINI, N.; R. HARRISON, and S. MILLARD (2003). "Monetary Policy Rules for Open Economies", Journal of Economics Dynamics and Control 27 (11-12), pp. 2059-2094.

CALVO, G. and C. REINHART (2000). "Fear of Floating", Quarterly Journal of Economics 117 (2), pp. $379-408$.

CAPUTO, R. (2004). "Persistence and the Role of Exchange Rate and Interest Rate Inertia in Monetary Policy", Central Bank of Chile Working Paper Series 300.

CAPUTO, R. (2005). "Exchange Rates, Inflation and Monetary Policy Objectives in Open Economies: the Experience of Chile" in Driver, R., P. Sinclair and C. Thoenissen (2005) Exchange Rates, Capital Flows and Policy, Routledge.

CAPUTO, R.; F. LIENDO, and J. MEDINA (2006). "New Keynesian Models for Chile in the Inflation Targeting Period: A Structural Investigation" in Mishkin, F. and K. Schmidt-Hebbel Monetary Policy under Inflation Targeting, Ninth Annual Conference of the Central Bank of Chile.

CESPEDES, L.; M. OCHOA, and C. SOTO (2005). "The New Keynesian Phillips Curve in an Emerging Market Economy: The Case of Chile”, Central Bank of Chile Working Paper Series 355.

CAPUTO, R. and F. LIENDO (2005). "Monetary Policy, Exchange Rate and Inflation Inertia in Chile: a Structural Approach", Central Bank of Chile Working Paper Series 352. 
CHRISTIANO, L.; M. EICHENBAUM, and C. EVANS (1999). "Monetary policy shocks: What have we learned and to what end?" in Taylor, J. and M. Woodford Handbook of Macroeconomics 1, pp. 149-234.

CHRISTIANO, L.; M. EICHENBAUM, and C. EVANS (2005). "Nominal Rigidities and the Dynamic Effects of a Shock to Monetary Policy", Journal of Political Economy 113 (1), pp. 1-45.

CLARIDA, R.; J. GALI, and M. GERTLER (1998). "Monetary Policy Rules in Practice: Some International Evidence", European Economic Review 42, pp. 1033-1067.

CLARIDA, R.; J. GALI, and M. GERTLER (2001). "Optimal Monetary Policy in Open vs. Closed Economies: An Integrated Approach", American Economic Review (Papers and Proceedings) 91 (2), pp. 248-252.

CLARIDA, R.; J. GALI, and M. GERTLER (2002). "A Simple Framework for International Monetary Policy Analysis", Journal of Monetary Economics 49 (5), pp. 879-904.

DENNIS, R. (2003). "Exploring the Role of the Real Exchange Rate in Australian Monetary Policy", The Economic Record 79 (244), pp. 20-38.

DEL NEGRO, M. and F. SCHORFHEIDE (2008). "Inflation dynamics in a small open-economy model under inflation targeting: some evidence from Chile", Staff Reports 329, Federal Reserve Bank of New York.

DUNGEY, M.; R. FRY; B. GONZALEZ-HERMOSILLO, and V. MARTIN (2002). "International Contagion Effects from the Russian Crisis and the LTCM Near-Collapse", IMF Working Paper WP/02/74.

FUHRER, J. and G. MOORE (1995). "Monetary Policy Trade-offs and the Correlation between Nominal Interest Rates and Real Output", American Economic Review 85 (1), pp 219-239.

FURHER, J. and G. MOORE (1995b). "Inflation Persistence", Quarterly Journal of Economics 110 (1), pp. $127-259$.

FUJII, E. and M. CHINN (2000). "Fin de Siecle Real Interest Rate Parity", NBER Working Paper W7880.

GALI, J. and M. GERTLER (1999). "Inflation Dynamics: A Structural Econometrics Analysis", Journal of Monetary Economic 44, pp. 195-222.

GALLEGO, F.; L. HERNANDEZ, and K. SCHMIDT-HEBBEL (2002). "Capital Controls in Chile: Where they Effective?" in Schmidt-Hebbel and Hernandez (editors) Banking, Financial Integration, and International Crisis, Sixth Annual Conference of the Central Bank of Chile.

GALI, J. and T. MONACELLI (2005). "Optimal Monetary Policy and Exchange Rate Volatility in a Small Open Economy”, Review of Economic Studies 72, pp. 707-734.

GARCIA, P.; L. HERRERA, and R. VALDES (2002). "New frontiers for Monetary Policy in Chile" in Loayza, N. and R. Soto (editors) Inflation Targeting: Design, Performance, Challenges, Fourth Annual Conference of the Central Bank of Chile.

HARVEY, A. and A. JAEGER (1993). "Detrending, Stylized Facts and the Business Cycle", Journal of Applied Econometrics 8, pp. 231-247.

JONAS, J. and F. MISHKIN (2003). "Inflation Targeting in Transition Economies: Experience and Prospects" in M. Woodford (ed.), Inflation Targeting, NBER Conference Series, University of Chicago Press (pp. 38).

KEATING, J. (1992). "Structural Approaches to Vector Autorregresions", Federal Reserve Bank of St. Louise Review, September/October, pp. 35-57.

KOZICKI, S. and P. TINSLEY (2002). "Dynamic specifications in optimizing trend-deviation macro models", Journal of Economic Dynamics and Control 26 (9-10), pp. 1585-1611.

LANDERRETCHE, O.; F. MORANDE, and K. SCHMIDT-HEBBEL (2000). "Inflation Targets and Stabilization in Chile" in Mahadeva, L. and G. Sterne (editors), Monetary Policy Frameworks in a Global Context, Routledge.

LEITEMO, K. and U. SODERSTROM (2005). "Simple Monetary Policy Rules and Exchange Rate Uncertainty”, Journal of International Money and Finance 24, pp. 481-507.

LUBIK, T. and F. SCHORFHEIDE (2007). "Do Central Banks Respond to Exchange Rate Movements? A Structural Investigation”, Journal of Monetary Economics 54 (4), pp. 1069-1087.

MCCONNELL, M. and G. PEREZ-QUIROS (2000). "Output Fluctuations in the United States: What Has Changed Since the Early 1980's?", American Economic Review 90 (5), pp. 1464-1476.

PARRADO, E. (2001). "External Shock and the Transmission of the Monetary Policy", Journal Economia Chilena 4 (3), pp. 29-57. 
PARRADO, E. and A. VELASCO (2002). "Alternative Monetary Rules in the Open Economy: A welfare Based Approach" in Loayza, N. and R. Soto (editors) Inflation Targeting: Design, Performance, Challenges, Fourth Annual Conference of the Central Bank of Chile.

SCHMIDT-HEBBEL, K. and M. TAPIA (2002). "Inflation Targeting in Chile", North American Journal of Economics and Finance 13, pp. 125-146.

SVENSSON, L. (2000). "Open-Economy Inflation Targeting”, Journal of International Economics 50 (1), pp. 155-183.

TAYLOR, J. (2001). "The Role of the Exchange Rate in Monetary-Policy Rules", American Economic Review 91 (2), pp. 263-267.

VALDES, R. (1997). "The Transmission of Monetary Policy in Chile", Central Bank of Chile Working Paper Series $\mathrm{N}^{\circ} 16$. 


\section{APPENDIX: DATA}

We use monthly data for the inflation targeting period in Chile; September 1990 to December 2000. The variables are;

$y_{t}$ : Real GDP deviation from trend. To compute this, we fit a structural time series model (STSM) to Chilean monthly output series, IMACEC. This last series can be obtained from the Chilean Central Bank (CCB). The STSM is fitted using the STAMP 6.0 software.

$\pi_{t}$ : Inflation deviation from target. The inflation series is CPI Chilean inflation (source CCB). The target series is available from Gallego, Hernandez and Schmidt-Hebbel (2002).

$q_{t}$ : $\quad$ Real exchange rate deviation from trend. The real exchange rate series, in levels, is taken from the CCB. Then, a STSM is fitted to obtain the deviation from trend.

$\rho_{t}$ : $\quad$ CCB's domestic real interest rate. From 1990 to 1995 is the indexed interest rate on the three months CCB instruments (PRBC 90), from 1995 to 2000 is the CCB's overnight indexed interest rate. Source: CCB.

$\rho_{t, n}: \quad$ Long-term real interest rate. This series is the indexed interest rate on eight years CCB instruments (PRC 8). Source: CCB.

$y_{t}^{*}$ : $\quad$ USA GDP deviation from trend. We use industrial production as a proxy (which is available on a monthly basis), and then detrended it with the Hodrick-Prescott filter.

$\rho_{t}^{*} \quad$ Short-term foreign real interest rate. We use the 180-day LIBO on dollars adjusted for six month ahead US inflation rate. Source: Gallego, Hernandez and Schmidt-Hebbel (2002).

Risk: Country risk premium. Is the premium on international bonds issued by Chilean corporations. This indicator is based on CCB information and JP Morgan Emerging Markets Bond Index. Source: Gallego, Hernandez and SchmidtHebbel (2002). 
